Behaviour

Elsevier Editorial system(tm) for Animal

Manuscript Draft

Manuscript Number: ANBEH-D-16-00994R2

Title: Slow to change? Individual fidelity to three-dimensional foraging habitats in southern elephant seals, Mirounga leonina

Article Type: UK Research paper

Corresponding Author: Dr. Trevor McIntyre,

Corresponding Author's Institution: University of Pretoria

First Author: Trevor McIntyre

Order of Authors: Trevor McIntyre; Marthán Bester; Horst Bornemann; Cheryl Tosh; Nico de Bruyn

Abstract: Slow to change? Individual fidelity to three-dimensional foraging habitats in southern elephant seals, Mirounga leonina

Long-term fidelity to foraging areas may have fitness benefits to individuals, particularly in unpredictable environments. However, such strategies may result in short-term energetic losses and delay responses to fast environmental changes. We used satellite tracking data and associated diving data to record the habitat use of nine individual southern elephant seals (Mirounga leonina) over 34 winter migrations. By assessing overlap in two- and three-dimensional home ranges we illustrate strong long-term (up to seven year) fidelity to foraging habitat. Furthermore, a repeatability statistic and hierarchical clustering exercise provided evidence for individual specialization of foraging migration strategies. We discuss the possible influences of stable longterm foraging migration strategies on the adaptability of individual elephant seals to rapid environmental change. Our results further illustrate the need for more long-term longitudinal studies to quantify the influence of individual-level site familiarity, fidelity and specialization on population-level resource selection and population dynamics. 
Title: Slow to change? Individual fidelity to three-dimensional foraging habitats in southern elephant seals, Mirounga leonina

Authors: Trevor McIntyre ${ }^{1}$ (corresponding author), Marthán N. Bester ${ }^{1}$, Horst Bornemann ${ }^{2}$, Cheryl A. Tosh ${ }^{1}$, P. J. Nico de Bruyn ${ }^{1}$

Addresses: $\quad$ 1. Mammal Research Institute, Department of Zoology and Entomology, University of Pretoria, Private Bag X20, Hatfield, 0028, South Africa.

2. Alfred Wegener Institute Helmholtz Centre for Polar and Marine Research, Biosciences, Bentho-Pelagic Processes, PO Box 120161, 27515 Bremerhaven, Germany.

Author for correspondence: Trevor McIntyre

e-mail: tmcintyre@ zoology.up.ac.za

tel: $+27(0) 124204608$ 
Editor

Animal Behaviour

Dear Editor

\section{SUBMISSION OF REVISED MANUSCRIPT}

Appended please find the revised manuscript now entitled: "Slow to change? Individual fidelity to three-dimensional foraging habitats in southern elephant seals, Mirounga leonina".

We have now completed a revision of the above-mentioned manuscript and addressed all of the editor's remarks as follows:

1. Put keywords in alphabetical order.

>> Done - please see Abstract document

2. Take the figures out of the text and upload them separately. Similarly, put all the tables together after the references. Figure captions should be collected together and placed after the references and tables in the manuscript. They must not be on the same page as the figure or uploaded as figures.

>> Done - please refer to the highlighted document.

3. Tables should have a short one-sentence title above the table and other information should be placed below the table.

>> Done - please refer to the highlighted document.

4. ' $\mathrm{N}$ ' should be a capital letter in italics.

>> Done - all places where this was done are highlighted in the highlight document.

5. Table 2. Remove the internal horizontal line.

>> Done. However, we retained an underlining of the "50\% 3D-UD" for clarity. Please advise should you require any further amendments here.

6. Use double line spacing in the references.

> Done.

7. For software references such as Calenge 2015 add the website address.

>> Done - please refer to the highlighted reference list.

We also attach a version of the new manuscript, highlighting the changes/corrections made, as well as a 'clean' version of the revised manuscript.

We trust that we have adequately addressed the all comments and wish to thank you again for your attention to this manuscript.

Trevor McIntyre \& co-authors

Mammal Research Institute, Department of Zoology \& Entomology

University of Pretoria, South Africa

Tel: $\quad+27-12-4204608$

Mobile: +27-78-0243511

E-mail: $\quad$ tmcintyre@ zoology.up.ac.za 


\section{Highlights}

- We recorded the oceanic behaviour of focal elephant seals over multiple years

- Seals displayed long-term fidelity to three-dimensional migration strategies

- Individual specialization was evident in foraging migrations

- The reported high fidelity may limit the adaptability of individuals 


\section{Introduction}

2 Many species display foraging site fidelity, returning repeatedly to the same foraging areas

3 (e.g. Augé, Chilvers, Moore, \& Davis, 2014; Weber et al., 2015), even when habitat quality is 4 sub-optimal (Krebs, 1971; Merkle, Cherry, \& Fortin, 2015). Fidelity to foraging areas may

5 have long-term advantages for individual fitness, particularly in unpredictable environments

6 (Switzer, 1993). For example, animals may return to foraging areas because they are familiar

7 with resources (Greenwood, 1980) and able to exploit comparatively productive areas,

8 resulting in long-term energetic gains. Animals may also return to certain areas because they

9 are familiar with potential refuges and able to avoid predation (Clarke et al., 1993; Forrester,

10 Casady, \& Wittmer, 2015). The benefits of long-term site fidelity may have short-term costs

11 if sufficient food cannot be found in temporally heterogeneous environments (Bradshaw,

12 Hindell, Sumner, \& Michael, 2004). More significant fitness costs of site fidelity may be

13 incurred when animals are unable to respond to short- and medium term changes in food

14 availability by switching between foraging patches (e.g. Newell, 1999; Whisson, Dixon,

15 Taylor, \& Melzer, 2016). Once an individual has learned a behaviour it may be hesitant to change or to adopt new foraging strategies, especially if the associated risks are great. The risks of looking for new foraging patches may be particularly great if foraging patches are far apart or are of unpredictable quality.

Individual animals sometimes display individual-level foraging fidelity, where the intra-individual variation in space use is less than the inter-individual variation in space use within a population (Wakefield et al., 2015). Individual-level foraging fidelity may be a type of individual specialization, best explained by phenotypic trade-offs when specialization in one strategy results in the inability to efficiently perform an alternative strategy (Bolnick et al., 2003). Various foraging behaviours such as prey recognition, capture ability, digestive 
capacity and predator avoidance strategies may be affected. The existence of individual-level specialization, in terms of site fidelity and dietary specialization, has long been recognized but rarely explicitly considered in ecological studies (Piper, 2011).

Foraging site fidelity has been widely illustrated in marine vertebrates, including marine birds (e.g. Baylis et al., 2015), turtles (e.g. Carman et al., 2016), fish (e.g. Gannon et al., 2015) and marine mammals (e.g. Vermeulen et al., 2016). Pinnipeds in particular often display high levels of foraging site fidelity (e.g. Arthur et al., 2015; Baylis et al., 2015; Wege, Tosh, de Bruyn, \& Bester, 2016). Fidelity to large-scale foraging areas was demonstrated for southern elephant seals (Mirounga leonina), but individual seals that were faithful to foraging areas did not show mass gain benefits (Bradshaw et al., 2004). However, it was proposed that returning to generally more productive areas could result in benefits over longer timescales (Bradshaw et al., 2004). Also, Authier et al. (2012) illustrated that lower variation in the isotopic foraging niche of male southern elephant seals covaried positively with estimated lifespans, thereby suggesting lifetime fitness benefits associated with foraging fidelity in this species. While these reports provide valuable insights, little information is available regarding the foraging area fidelity of individual elephant seals over the long term (3+ years) and no information exists on fidelity to specific foraging strategies used to exploit the vertical dimension.

Animal space use is typically quantified in two dimensions, despite the fact that most animals also use space in a vertical dimension (i.e. by flying, diving or burrowing). Incorporating the vertical component into representations of space use may provide novel ecological insights and have conservation management benefits (Tracey et al., 2014). Habitat use studies have attempted to incorporate the vertical dimension through separate analyses of 
vertical metrics without incorporating spatial position (2-dimensions). Some recent studies, particularly on marine predators, have incorporated the vertical behaviour component (e.g. spherical first-passage time, Bailleul, Lesage, \& Hammill, 2010). More recently, three dimensional utilization distributions (3D UDs) quantified vertical space use and home range overlap of sharks (Simpfendorfer, Olsen, Heupel, \& Moland, 2012) and birds (Cooper, Sherry, \& Marra, 2014).

Southern elephant seals have a circumpolar distribution and their foraging behaviour is closely linked to their specific haul-out sites (Hindell et al., 2016). Elephant seals display a high degree of fidelity to their haul-out sites (Hofmeyr, Kirkman, Pistorius, \& Bester, 2012), which may be an important indication of learned behaviour in these animals. Here we assess (1) the persistence of migration site fidelity in southern elephant seals; (2) fidelity to a threedimensional environment, particularly the water depths exploited; and (3) the individual repeatability and specialization of migration strategies. We predicted that foraging site fidelity in elephant seals would decay over the long-term, due to the spatiotemporally patchy nature of their prey distribution (i.e. that site fidelity would persist only as long as prey patches persist - Kamil, 1983). Fidelity to three-dimensional environments was expected to be lower, both as a result of variation in the vertical distribution of prey items, as well as the influences of physiological development and ageing on the dive capacity of seals. Finally, the propensity for Marion Island's elephant seals to forage in deep ocean areas, south-west of the island (Hindell et al., 2016; Oosthuizen, Bester, Altwegg, McIntyre, \& de Bruyn, 2015) led to a prediction of limited individual-level specialization in migration strategies.

\section{Ethical Note}


The research described refers to an Antarctic seal species, the southern elephant seal. It conforms to Antarctic Treaty legislation and to the SCAR Code of Conduct for the Use of Animals for Scientific Purposes in Antarctica (ATCM XXXIV 2011). We adhere to the 'Guidelines for the use of animals in research' as published in Animal Behaviour (1990, 41, 183-186) and the laws of the country where the research was conducted. All flipper tagging and satellite device deployment/retrieval procedures were reviewed and approved by the Animal Use and Care Committee and more recently the renamed Animal Ethics Committee of the University of Pretoria (AUCC 040827-024; AUCC 040827-023 and EC077-15), and fieldwork was performed under Prince Edward Island's Research Permits R8-04 and R04-08. All dive and track data are available via the PANGAEA Data Publisher for Earth \& Environmental Science (doi:10.1594/PANGAEA.871448).

\section{Track data and filtering}

As part of a series of tracking projects between April 2004 and February 2013, we deployed 95 satellite-relay data loggers (either Series 9000 SRDLs, or CTD-SRDLs, Sea Mammal Research Unit, University of St Andrews, Scotland) on southern elephant seals of both sexes hauled out at sub-Antarctic Marion Island ( $\left.46^{\circ} 54^{\prime} \mathrm{S} ; 37^{\circ} 45^{\prime} \mathrm{E}\right)$. These instruments provided track locations (obtained via Service Argos estimates), basic time-depth profiles of approximately 20 dives per day and a maximum of four temperature-depth profiles per day (Boehme et al., 2009). were immobilized using a handheld syringe, extended by a length of drip-tubing, to deliver a calculated dose of ketamine based on a visual estimation of the seal's mass (Bester, 1988). Seals were then observed from a distance until the anticipated end of the induction period 
(about 20 min post-injection), and then approached for the first time to assess the depth of anaesthesia by evaluating reactions to stimuli (e.g. slight noise and touch) (Bornemann et al., 2013). As soon as the seals tolerated physical stimuli, their eyes were covered with a towel to protect against solar radiation and minimise unnecessary stimuli. Transmitters were glued onto the fur of the heads of the seals using a quick-setting epoxy resin (Field et al., 2012). The heaviest of these devices (CTD-SRDLs) weighed $545 \mathrm{~g}$, representing $0.19 \%$ of the average post-moult departure mass of female elephant seals from this population (Postma, Bester, \& De Bruyn, 2013). After their post-migration return to the island, data transmitting devices were either removed from sedated animals by shaving them off the fur or shed naturally with the pelage during the annual moult. No short-term deleterious effects were evident with immobilization, device deployment or retrieval, while tracking devices attached to elephant seals are known not to affect individual mass gain or survival in the long term (McMahon, Field, Bradshaw, White, \& Hindell, 2008). We report on a subset of the resultant dataset, after retaining data from 34 post-moult migrations (as opposed to post-breeding migrations, Le Boeuf \& Laws, 1994) from nine individual seals (two males and seven females) that successfully carried instruments over multiple winter migrations (Table 1). Only tracks with data for a minimum period of 30 days were included. Seals in this sample provided tracking and dive data for a median of three migrations (range: $2-7$ ), each migration covering a median period of 223 days (range: $38-292$ ).

All statistical analyses were undertaken in the R programming environment (Team, 2016). Track data were filtered to remove estimated locations that required swim speeds in excess of $3.5 \mathrm{~m} / \mathrm{s}$ and/or creating spikes in the track with angles smaller than $15^{\circ}$ and $25^{\circ}$ with extensions greater than 2,500 m and 5,000 m, respectively (Freitas, Lydersen, Fedak, \& Kovacs, 2008). 
Inter-annual and multi-year fidelity

Fidelity to home ranges was expressed as the overlap in $95 \%$ kernel density utilization distributions (UD) of two dimensional location data (latitude and longitude) and three dimensional diving data (latitude, longitude and dive depth). The two dimensional UDs were calculated using an ad hoc smoothing parameter, which assumes a bivariate normal UD in the R package 'adehabitatHR' (Calenge, 2015). Overlap of two-dimensional UDs was calculated following Arthur et al. (Arthur et al., 2015), using Bhattacharyya's affinity (BA) for a general measure of similarity between UD estimates.

Daily median dive depth values were calculated for each two dimensional location to create a three dimensional dataset. We divided the datasets into daytime and nocturnal dives, as southern elephant seals often display diel vertical migration (e.g. Biuw et al., 2010; McIntyre, Bornemann, Plötz, Tosh, \& Bester, 2011). Three dimensional kernel density utilisation distributions (3D-UD) were estimated in the ' $k s$ ' package (Duong, 2016), using a two-stage plug-in method, developed by Duong and Hazelton (2003) and applied by Simpfendorfer et al. (2012) and Cooper et al. (2014) amongst others. We calculated overlap in 95\% 3D-UDs both inter-annually and over multiple years (multi-year) for individual seals, following Simpfendorfer et al. (2012). Inter-annual overlap is the overlap for tracks from consecutive years (e.g. overlap between 2006 and 2007; 2007 and 2008 etc.), while multiyear overlap was calculated between tracks separated by a year or more (e.g. overlap between 2006 and 2008; 2006 and 2009 etc.).

\section{Repeatability}


We applied a repeatability statistic to a series of track and behavioural metrics to assess individual behavioural consistency compared to the behaviours displayed by all the seals in the dataset. This repeatability statistic was calculated, making use of an intra-class correlation coefficient (Wolak, Fairbairn, \& Paulsen, 2012), following McFarlane Tranquila et al. (2014). Accordingly, among-groups variance $\left(s_{A}^{2}\right)$ and within-individual variance components $\left(s^{2}\right)$ are derived from a linear mixed-effects model (R package 'psychometric'). Repeatability $(r)$ was then calculated as:

$$
r=\frac{s_{A}^{2}}{\left(s^{2}+s_{A}^{2}\right)}
$$

where high $r$ values (>0.5) indicate consistent individual behaviours.

The repeatability statistic was applied to the following track and behavioural metrics: (1) the daytime and nocturnal 95\% and 50\% 3D-UDs incorporating the dive depths of tracked seals; (2) the maximum distance travelled away from Marion Island per migration and (3) the bearing of the location at the maximum distance away from Marion Island.

\section{Hierarchical clustering}

We explored the possibility of individually specific migration strategies (consistent long term behaviour) using a hierarchical clustering approach. A principal components analysis (PCA) was first applied to a series of track- and dive metrics to generate a single metric representative of an overall strategy. Six daily metrics were included in the PCA: (1) median daytime dive depth; (2) median night-time dive depth; (3) diel vertical migration (defined as the difference between daytime and night-time median dive depths); (4) distance from Marion Island; (5) bearing from Marion Island; and (6) mean speed of travel (mean speed of travel between all locations associated with a specific day). The first five principal components explained $93.7 \%$ of the variance. The relative contribution of each principal 
component to a single, weighted metric was determined from the loadings of the PCA output.

This value was used in a hierarchical clustering analysis, using Ward's clustering criterion (Ward, 1963) on a Euclidean distance matrix.

\section{Results}

\section{Home range overlap}

Seven of the nine seals tracked over multiple migrations had overlapping 95\% UDs that encompassed more than $50 \%$ of their home ranges (UD overlap > 0.5) (Fig. 1). Two individual seals tracked twice in non-consecutive years (RR217:2009, 2011 and YY039:2008, 2011), had comparatively disparate UDs, characterised by small areas of overlap (0.31 and 0.19 respectively, Table 1). Mean inter-annual overlap of 95\% UDs was $0.73 \pm 0.14$ (Table 1). Overlap of UDs for multi-year periods were slightly lower at $0.61 \pm$ 0.18. Inter-annual overlap of 95\% UDs was consistently high for individuals tracked over consecutive migrations, with a minimum overlap of $0.65 \pm 0.17$ (maximum of $0.91 \pm 0.03$ ). Multi-year overlap was more variable, ranging from 0.19 to 0.92 (Table 1).

\section{Three-dimensional UD overlap}

The mean inter-annual overlap of 95\% 3D-UDs was $0.54 \pm 0.15$ for daytime dives and $0.57 \pm$ 0.15 for nocturnal dives. Overlap was slightly lower for multi-year periods at $0.45 \pm 0.17$ for daytime dives and $0.47 \pm 0.15$ for nocturnal dives. Five of the six seals that were tracked in consecutive years, recorded 95\% 3D-UDs that overlapped by $60 \%-71 \%$. Individual variation was evident, with some seals using very similar three-dimensional spaces over long time periods (e.g. YY189, Fig. 2, Table 2), while others used slightly different depths between years (e.g. GG335, Fig. 2, Table 2) and others used completely different depths (e.g. PO225, Fig. 2, Table) despite substantial overlap in the two dimensional 95\% UD (Fig. 1). 
Areas of restricted movement or 50\% 3D-UDs overlapped much less and was more variable between seals (Table 2), although two seals (PO043 and OO052) had similar areas of restricted movement and diving behaviours in consecutive years (50\% 3D-UDs overlap $=$ approximately $60 \%)$.

Two seals (PO225 and GG335) used similar oceanographic areas (2-D UD) (Fig. 1) but had very different diving behaviours (3-D -UD) (Fig. 2) in their subsequent migrations. GG335 dived to varied depths but maintained a substantial overlap in 3D-UDs over the 5 years that it was tracked. This seal employed two general diving strategies, performing deeper dives in the last two migrations $(2011,2012)$, compared to the preceding three years (Fig. 2). PO225 dived to variable depths during its 2007 migration but used more specific depth layers in 2011.

\section{Repeatability}

All repeatability $(r)$ values were larger than 0.5 (Table 3 ), suggesting consistency in individual behaviours. The lowest value (0.53) was calculated for track bearings of the point furthest away from Marion Island, indicating least consistency for this metric. All other $r$ values were equal to or larger than 0.6 (Table 3), indicating high levels of consistency in the three-dimensional area sizes used by seals and distances travelled away from Marion Island.

\section{Hierarchical clustering}

Five principal components (PCs) explained $93.7 \%$ of the variance in our dataset and included both horizontal movement and vertical dive behaviour metrics. PC1 was most strongly associated with DVM, PC2 with distance and bearing from Marion Island + night-time dive 
depths, PC3 with daytime dive depths, PC4 with travel speed and PC5 with bearing and distance.

Hierarchical clustering revealed three distinct migration strategies used by the tracked seals (Fig. 3), and multiple tracks of individual seals tended to group together in the same clusters (e.g. OO052, GG335). Two individuals (WW061 and RR217) grouped in two different clusters. Seals grouping into specific clusters generally foraged in the same areas. For example, GG335 (2007) and WW061 (2008) both travelled in a westerly direction away from Marion Island (and further), compared to their other migrations (Fig. 1). These migrations clustered with all of the migrations recorded for OO021 (Fig. 3), which used a similar spatial area (Fig. 1).

Migrations in cluster 1 (C1) covered a wide latitudinal range, from the Subtropical Front in the north to south of the APF (Fig. 3). Migrations in cluster 3 (C3) were characterised by the greatest distances away from Marion Island, but restricted to latitudes south of the Subantarctic Front, with many of the tracks concentrated south of the Antarctic Polar Front (APF). Cluster two (C2) comprised of tracks from one seal (OO052), which used a small area adjacent to Marion Island during all five of its post-moult migrations.

\section{Discussion}

Studies of fidelity to migration strategies over long-distances and long time periods, are often restricted to few migrations (e.g. two or three) (Mingozzi, Mencacci, Cerritelli, Giunchi, \& Luschi, 2016), although a few recent studies have successfully tracked seasonally migrating birds over multiple years (e.g. Berthold et al., 2002; Lopez-Lopez et al., 2014; Vardanis, Nilsson, Klaassen, Strandberg \& Alerstam, 2016). Similarly, individual foraging site fidelity 
in elephant seals has only been studied from a small number of migrations, not separated by more than one or two years (e.g. Bradshaw et al., 2004; Simmons, 2008). In one study, a single northern elephant seal, M. angustirostris, followed the same path in 2006 as it did 11 years previously in 1995; although the North American continent predisposes migration by this species to a westerly bearing away from haulout sites (Costa, Breed, \& Robinson, 2012). Our study followed a small number of individual seals and reports on continued fidelity over long distances and time periods not reported before. Seals tracked in our sample showed high overlap in $95 \%$ UDs, even over extended periods of up to seven years - averaging more than $60 \%$ for both consecutive and non-consecutive migrations (Table 1). The long-term fidelity to oceanographic areas used by seals included their use of the vertical environment, and overlap in $95 \%$ 3D-UDs averaged more than $45 \%$ over multi-year comparisons and more than $50 \%$ for consecutive years.

Individual-level flexibility in inter-annual migration routes has been illustrated for some migrating birds known to forage on prey items that are variably distributed (Vardanis, Nilsson, Klaassen, Strandberg \& Alerstam, 2016), although the drivers of such flexibility remain unknown. Bradshaw at al. (2004) were unable to link foraging success of tracked southern elephant seals to the likelihood that they would alter their foraging strategies, suggesting that elephant seals do not follow the win-stay/lose-switch rule (Shields, Cook, Hebblethwaite, \& Wiles-Ehmann, 1988) over shorter time periods. Alternatively, they suggested that elephant seals would benefit over longer periods by returning to areas with generally increased productivity. While the condition of seals tracked in our sample is unknown and we were unable to assess the impacts of migration strategies, the long-term fidelity to migration patterns and oceanographic areas apparently supports the hypothesis of Bradshaw et al. (2004) that the win-stay/lose-switch rule does not apply over multiple 
migrations in elephant seals. However, the reasonably small sample size we report on here does not exclude the possibility that tracked seals rarely encountered such poor foraging success as to prompt any switches in strategy.

Two seals in our sample (PO225 and GG335) displayed much more overlap in their 2D UDs, compared to their 3-D UDs (Figs. 1 and 2). GG335 evidently switched its depth use strategy once between 2010 and 2011, performing deeper dives in 2011 and 2012 when compared to the earlier tracks. The two migrations of PO225 (2007; 2011) were 3 years apart, limiting any hypotheses on the development of dive behaviour. However, it is unlikely that the observed differences in diving behaviour are due to ontogenic development of diving capacity (Bennett, McConnell, \& Fedak, 2001), because this seal was first tracked as an adult, eight year old male and diving capacity does not develop substantially once a seal reaches maturity (Grundling, 2014). Elephant seal dive strategies may change withinmigrations (e.g. Bester, Bornemann, \& McIntyre, in press; Biuw et al., 2010; McIntyre, Ansorge, et al., 2011), indicating that elephant seals are often able to exploit localised prey patches at different depths. The dissimilar diving behaviour seen in different migrations of PO225 and GG335 further suggests an element of inter-annual plasticity in foraging strategies. Long-term longitudinal tracking investigations are needed to explore these shifts in diving strategies.

$$
\text { Seal behaviours in our study showed high levels of individual repeatability }(r) \text {. }
$$

Combined with the outputs of the clustering exercise, these results suggest a high level of individual specialization in migration behaviour. Individual variation in southern elephant seal behaviours, and other marine predators, has been acknowledged and recently accounted for in behavioural modelling exercises (e.g. Farnsworth et al., 2015; Massie et al., 2016; 
Stillfried, Belant, Svoboda, Beyer, \& Kramer-Schadt, 2015). Moreover, recent studies have illustrated consistency and specialization in individual behaviour (e.g. Wakefield et al., 2015). Southern elephant seals employ various foraging strategies, exploiting shallow water masses associated with the Kerguelen Plateau, and the Antarctic Peninsula, or using deep, open water regions in the Southern Ocean (Hindell et al., 2016). Female elephant seals in the Antarctic Peninsula region display individual behavioural and foraging niche specialization with substantial within-migration behavioural plasticity (Hückstädt et al., 2012). Similarly, Marion Island elephant seals use three broad migration strategies (clusters) (Fig. 3), which were identified from diel vertical migration patterns, dive depths, and distance and bearing from Marion Island.

\section{Implication of long-term fidelity and individual specialization}

The Southern Ocean is rapidly changing with a generally warming and freshening trend leading to expected poleward shifts in the distribution of lower trophic level consumers (Constable et al., 2014). The long-term spatial fidelity of elephant seals, including threedimensional environments (this study), has potential implications for our understanding of their behavioural response to disturbance. The origin of fidelity described here is unknown and is not analysed in detail. However, site familiarity and fidelity may develop if juvenile elephant seals are successful during their first foraging migration (Bradshaw et al., 2004).

This would suggest that environmental conditions experienced in early migrations may have consequences for future migration strategies (Dall, Bell, Bolnick, \& Ratnieks, 2012). Juvenile southern elephant seals tracked from Marion Island generally travel due west, irrespective of year, and focus their foraging behaviour along bathymetric features, frontal zones and mesoscale eddies (Tosh et al., 2012; 2015), adding to their familiarity of the surrounding ocean.

While the intra-migration dive behaviour of southern elephant seals is known to respond to 
changes in the temperature structure of the water column and associated changes in the distribution of potential prey items (Guinet et al., 2014; McIntyre, Ansorge, et al., 2011), the long-term fidelity to foraging areas and diving behaviour may limit coarser-scale movement and behavioural adaptations of individual elephant seals to rapid environmental changes, although this requires further investigation. Similarly, other taxa such as seabirds and marine turtles, which rely on site-specific information gained early in life, may be more vulnerable to rapid environmental change and other anthropogenic disturbances (Hipfner, 2008; Vander Zanden et al., 2016; Wakefield et al., 2015). Future research needs to elucidate the role of long-term behavioural adaptations in individual elephant seals in response to rapid environmental change, particularly through long-term longitudinal monitoring of fitness consequences associated with behavioural changes in relation to environmental differences.

Our results show the value of long-term data on known individuals for illustrating individual repeatability, and potentially specialization, in the migration strategies of animals. Tracking studies are often used for conservation planning and environmental management purposes (e.g. Jabour et al., 2016). Such studies can benefit from incorporating seasonal variation in habitat use of target species (Braham et al., 2015), as well as samples representing substantial spatial variation (Mazor, Beger, Mcgowan, Possingham, \& Kark, 2016). However, while the influence of individual differences on our understanding of animal ecology is recognised (Dall et al., 2012), it is seldom implemented in population-level studies. Bolnick et al (2011) highlights that individual specialisation or phenotypic expression can have serious implications for studies on the ecology, evolution and conservation of populations. For example, resource selection models which assume foragers are informed about their total surroundings to select the most favourable areas would benefit from incorporating effects associated with individual familiarity and fidelity (Wakefield et al., 
348 2015). Our study provides further support to the call for long-term longitudinal research

349 quantifying the influence of site familiarity, site fidelity and resource specialization on animal 350 population dynamics.

351

352 
Arthur, B., Hindell, M., Bester, M., Trathan, P., Jonsen, I., Staniland, I., ... Lea, M.-A. (2015). Return customers: foraging site fidelity and the effect of environmental variability in wide-ranging Antarctic fur seals. Plos One, 10, e 0120888. doi:10.1371/journal.pone.0120888

ATCM (2011) SCAR's Code of Conduct for the Use of Animals for Scientific Purposes in Antarctica. IP53, Agenda Item CEP 8c, presented by SCAR during XXXIV Antarctic Treaty Consultative Meeting, Buenos Aires, Argentina, 20 June - 21 July 2011, 4pp. http://www.scar.org/scar_media/documents/science/atcm34_ip053_CofC_Animals.pdf

Augé, A. A., Chilvers, B. L., Moore, A. B., \& Davis, L. S. (2014). Importance of studying Conservation, 17, 61-71. doi:10.1111/acv.12056

Authier, M., Bentaleb, I., Ponchon, A., Martin, C., \& Guinet, C. (2012). Foraging fidelity as a recipe for a long life: foraging strategy and longevity in male southern elephant seals. PloS One, 7(4), e32026. doi:10.1371/journal.pone.0032026

Bailleul, F., Lesage, V., \& Hammill, M. O. (2010). Spherical First Passage Time: A tool to investigate area-restricted search in three-dimensional movements. Ecological Modelling, 221, 1665-1673.

Baylis, A. M. M., Orben, R. A., Arnould, J. P. Y., Peters, K., Knox, T., Costa, D. P., \& Staniland, I. J. (2015). Diving deeper into individual foraging specializations of a large marine predator, the southern sea lion. Oecologia, 179(4), 1053-1065. doi:10.1007/s00442-015-3421-4

Baylis, A. M. M., Orben, R. A., Pistorius, P., Brickle, P., Staniland, I., \& Ratcliffe, N. (2015). Winter foraging site fidelity of king penguins breeding at the Falkland Islands. Marine Biology, 162, 99-110. doi:10.1007/s00227-014-2561-0 
Bennett, K. A., McConnell, B. J., \& Fedak, M. (2001). Diurnal and seasonal variations in the duration and depth of the longest dives in southern elephant seals (Mirounga leonina): possible physiological and behavioural constraints. Journal of Experimental Biology, 204, 649-662.

Berthold, P., v. d. Bossche, W., Jakubiec, Z., Kaatz, C., Kaatz, M. \& Querner, U. (2002). Long-term satellite tracking sheds light upon variable migration strategies of White Storks (Ciconia ciconia). Journal of Ornithology, 143, 489-495.

Bester, M. N. (1988). Marking and monitoring studies of the Kerguelen stock of southern elephant seals Mirounga leonina and their bearing on biological research in the Vestfold Hills. Hydrobiologia, 165, 269-277.

Bester, M. N., Bornemann, H., \& McIntyre, T. (n.d.). Antarctic marine mammals and sea ice. In D. N. Thomas \& G. S. Dieckman (Eds.), Sea Ice (3rd ed.). Oxford: Wiley-Blackwell.

Biuw, M., Nøst, O. A., Stien, A., Zhou, Q., Lydersen, C., \& Kovacs, K. M. (2010). Effects of hydrographic variability on the spatial, seasonal and diel diving patterns of southern elephant seals in the eastern Weddell Sea. PLoS ONE, 5(11), e13816. doi:10.1371/journal.pone.0013816

Boehme, L., Lovell, P., Biuw, M., Roquet, F., Nicholson, J., Thorpe, S. E., ... Fedak, M. (2009). Technical Note: Animal-borne CTD-Satellite Relay Data Loggers for real-time oceanographic data collection. Ocean Science, 5, 685-695.

Bolnick, D. I., Amarasekare, P., Araujo, M. S., R, B., Levine, J. M., Novak, M., ... Vasseur, D. A. (2011). Why intraspecific trait variation matters in community ecology. Trends in Ecology and Evolution, 26(4), 183-192. doi:10.1016/j.tree.2011.01.009

Bolnick, D. I., Svanbäck, R., Fordyce, J. A., Yang, L. H., Davis, J. M., Hulsey, C. D., \& Forister, M. L. (2003). The ecology of individuals: incidence and implications of individual specialization. The American Naturalist, 161(1), 1-28. 
Bradshaw, C. J. A., Hindell, M. A., Sumner, M. D., \& Michael, K. J. (2004). Loyalty pays: potential life history consequences of fidelity to marine foraging regions by southern elephant seals. Animal Behaviour, 68, 1349-1360.

Braham, M., Miller, T., Duerr, A. E., Lanzone, M., Fesnock, A., LaPre, L., ... Katzner, T. (2015). Home in the heat: Dramatic seasonal variation in home range of desert golden eagles informs management for renewable energy development. Biological Conservation, 186, 225-232. doi:10.1016/j.biocon.2015.03.020

Calenge, C. (2015). Home Range Estimation in R : the adehabitatHR Package. Retrieved from https://cran.r-project.org/web/packages/adehabitatHR/index.html

Carman, V. G., Bruno, I., Maxwell, S., Álvarez, K., Albareda, D., Acha, E. M., \& Campagna, C. (2016). Habitat use, site fidelity and conservation opportunities for juvenile loggerhead sea turtles in the Río de la Plata, Argentina. Marine Biology, 163. doi:10.1007/s00227-015-2795-5

Clarke, M. F., da Silva, K. B., Lair, H., Pocklington, R., Kramer, D. L., \& McLaughlin, R. L. (1993). Site familiarity affects escape behaviour of the eastern chipmunk, Tamias striatus. Oikos, 66(3), 533-537.

Constable, A. J., Melbourne-Thomas, J., Corney, S. P., Arrigo, K. R., Barbraud, C., Barnes, D. K. A., ... Ziegler, P. (2014). Climate change and Southern Ocean ecosystems I : how changes in physical habitats directly affect marine biota. Global Change Biology. doi:10.1111/gcb.12623

Cooper, N. W., Sherry, T. W., \& Marra, P. P. (2014). Modeling three-dimensional space use and overlap in birds. Auk, 131, 681-693. doi:10.1642/AUK-14-17.1

Costa, D. P., Breed, G. A., \& Robinson, P. W. (2012). New insights into pelagic migrations : implications for ecology and conservation. Annual Review of Ecology, Evolution, and Systematics, 43, 73-96. doi:10.1146/annurev-ecolsys-102710-145045 
Dall, S. R. X., Bell, A. M., Bolnick, D. I., \& Ratnieks, F. L. W. (2012). An evolutionary ecology of individual differences. Ecology Letters, 15, 1189-1198. doi:10.1111/j.14610248.2012.01846.x

de Bruyn, P. J. N., Tosh, C. A., Oosthuizen, W. C., Phalanndwa, M. V, \& Bester, M. N. (2008). Temporary marking of unweaned southern elephant seal (Mirounga leonina L.) pups. South African Journal of Wildlife Research, 38(2), 133-137.

Duong, T. (2016). Package "ks". Retrieved from https://cran.rproject.org/web/packages/ks/index.html

Duong, T., \& Hazelton, M. (2003). Plug-in bandwidth matrices for bivariate kernel density estimation. Journal of Nonparametric Statistics, 15(1), 17-30. doi:10.1080/10485250306039

Farnsworth, M. L., Dickson, B. G., Zachmann, L. J., Hegeman, E. E., Cangelosi, A. R., Jackson, T. G. J., \& Scheib, A. F. (2015). Short-term space-use patterns of translocated Mojave desert tortoise in southern California. PLoS ONE, 10(9), e0134250. doi:10.1371/journal.pone. 0134250

Field, I. C., Harcourt, R. G., Boehme, L., Bruyn, P. J. N. De, Charrassin, J.-B., McMahon, C. R., ... Hindell, M. a. (2012). Refining instrument attachment on phocid seals. Marine Mammal Science, 28(3), E325-E332. doi:10.1111/j.1748-7692.2011.00519.x

Forrester, T. D., Casady, D. S., \& Wittmer, H. U. (2015). Home sweet home: fitness consequences of site familiarity in female black-tailed deer. Behavioral Ecology and Sociobiology, 69, 603-612. doi:10.1007/s00265-014-1871-z

Freitas, C., Lydersen, C., Fedak, M., \& Kovacs, K. M. (2008). A simple new algorithm to filter marine mammal Argos locations. Marine Mammal Science, 24(2), 315-325.

Gannon, R., Payne, N. L., Suthers, I. M., Gray, C. A., Meulen, D. E. Van Der, \& Taylor, M. D. (2015). Fine-scale movements, site fidelity and habitat use of an estuarine dependent 
Greenwood, B. Y. P. J. (1980). Mating systems, philopatry and dispersal in birds and mammals. Animal Behaviour, 28, 1140-1162.

Grundling, A. (2014). Ontogeny of southern elephant seal (Mirounga leonina) dive behaviour. B.Sc. hons. thesis, University of Pretoria.

Guinet, C., Vacquié-garcia, J., Picard, B., Bessigneul, G., Lebras, Y., Dragon, A. C., ... and light conditions : insight into prey distribution. Marine Ecology Progress Series, 499, 285-301. doi:10.3354/meps 10660

Hindell, M. A., McMahon, C. R., Bester, M. N., Boehme, L., Costa, D., Fedak, M. A., ... Charrassin, J.-B. (2016). Circumpolar habitat use in the southern elephant seal: implications for foraging success and population trajectories. Ecosphers, 7(May), e01213. doi:10.1002/ ecs2.1213

Hipfner, J. M. (2008). Matches and mismatches: ocean climate, prey phenology and breeding success in a zooplanktivorous seabird. Marine Ecology Progress Series, 368, 295-304. doi:10.3354/meps07603

Hofmeyr, G. J. G., Kirkman, S. P., Pistorius, P. A., \& Bester, M. N. (2012). Natal site fidelity by breeding female southern elephant seals in relation to their history of participation in the winter haulout. African Journal of Marine Science, 34(3), 373-382.

Hückstädt, L. A., Koch, P. L., McDonald, B. I., Goebel, M. E., Crocker, D. E., \& Costa, D. P. (2012). Stable isotope analyses reveal individual variability in the trophic ecology of a top marine predator, the southern elephant seal. Oecologia, 169(2), 395-406. doi:10.1007/s00442-011-2202-y 
Jabour, J., Lea, M.-A., Goldsworthy, S. D., Melcher, G., Sykes, K., \& Hindell, M. A. (2016). Marine telemetry and the conservation and management of risk to seal species in Canada and Australia. Ocean Development \& International Law, 47(3), 255-271. doi:10.1080/00908320.2016.1194094

Kamil, A. C. (1983). Optimal foraging theory and the psychology of learning. American Zoologist, 23(2), 291-302.

Krebs, J. R. (1971). Territory and breeding density in the Great Tit, Parus Major L. Ecology, $52(1), 2-22$.

Le Boeuf, B. J., \& Laws, R. M. (1994). Elephant Seals: Population Ecology, Behavior, and Physiology. Berkeley: University of California Press. doi:http://ark.cdlib.org/ark:/13030/ft7b69p131/

López-López, P., García-Ripollés, C. \& Urios, V. (2014). Individual repeatability in timing and spatial flexibility of migration routes of trans-Saharan migratory raptors. Current Zoology, 60(5), 642-652.

Massie, P. P., McIntyre, T., Ryan, P. G., Bester, M. N., Bornemann, H., \& Ansorge, I. J. (2016). The role of eddies in the diving behaviour of female southern elephant seals. Polar Biology, 39, 297-307. doi:10.1007/s00300-015-1782-0

Mazor, T., Beger, M., Mcgowan, J., Possingham, H. P., \& Kark, S. (2016). The value of migration information for conservation prioritization of sea turtles in the Mediterranean. Global Ecology and Biogeography, 25, 540-552. doi:10.1111/geb.12434

McFarlane Tranquilla, L. A., Montevecchi, W. A., Fifield, D. A., Hedd, A., Gaston, A. J., Robertson, G. J., \& Phillips, R. A. (2014). Individual winter movement strategies in two species of Murre (Uria spp.) in the Northwest Atlantic. PLoS ONE, 9(4). doi:10.1371/journal.pone.0090583 
McIntyre, T., Ansorge, I. J., Bornemann, H., Plötz, J., Tosh, C. A., \& Bester, M. N. (2011). Elephant seal dive behaviour is influenced by ocean temperature: implications for climate change impacts on an ocean predator. Marine Ecology Progress Series, 441, 257-272. doi:10.3354/meps09383

McIntyre, T., Bornemann, H., Plötz, J., Tosh, C. A., \& Bester, M. N. (2011). Water column use and forage strategies of female southern elephant seals from Marion Island. Marine Biology, 158(9), 2125-2139. doi:10.1007/s00227-011-1719-2

McMahon, C. R., Field, I. C., Bradshaw, C. J. A., White, G. C., \& Hindell, M. A. (2008). Tracking and data-logging devices attached to elephant seals do not affect individual mass gain or survival. Journal of Experimental Marine Biology and Ecology, 360, 7177.

Merkle, J. A., Cherry, S. G., \& Fortin, D. (2015). Bison distribution under conflicting foraging strategies: site fidelity vs. energy maximization. Ecology, 96(7), 1793-1801.

Mingozzi, T., Mencacci, R., Cerritelli, G., Giunchi, D., \& Luschi, P. (2016). Living between widely separated areas: Long-term monitoring of Mediterranean loggerhead turtles sheds light on cryptic aspects of females spatial ecology. Journal of Experimental Marine Biology and Ecology, 485, 8-17. doi:10.1016/j.jembe.2016.08.007

Newell, G. R. (1999). Responses of Lumholtz's tree-kangaroo ( Dendrolagus lumholtzi ) to loss of habitat within a tropical rainforest fragment. Biological Conservation, 91, 181189.

Oosthuizen, W. C., Bester, M. N., Altwegg, R., McIntyre, T., \& de Bruyn, P. J. N. (2015). Decomposing the variance in southern elephant seal weaning mass: partitioning environmental signals and maternal effects. Ecosphere, 6(August), 1-22.

Piper, W. H. (2011). Making habitat selection more "familiar" : a review. Behavioral Ecology and Sociobiology, 65, 1329-1351. doi:10.1007/s00265-011-1195-1 
Postma, M., Bester, M. N., \& De Bruyn, P. J. N. (2013). Spatial variation in female southern elephant seal mass change assessed by an accurate non-invasive photogrammetry method. Antarctic Science, 25(6), 731-740. doi:10.1017/S0954102013000059

R Core Team (2016). R: A language and environment for statistical computing. R Foundation for Statistical Computing, Vienna, Austria. Retrieved from http://www.r-project.org

Shields, W. M., Cook, J. R., Hebblethwaite, M. L., \& Wiles-Ehmann, S. S. (1988). Ideal free coloniality in the swallows. In C. N. Slobodchikolf (Ed.), The Ecology of Social Behavior (pp. 189-228). San Diego: Academic Press.

Simmons, S. E. (2008). Environmental and individual effects on the foraging success of an apex predator, the northern elephant seal (Mirounga angustirostris). Ph.D. thesis, University of California, Santa Cruz.

Simpfendorfer, C. A., Olsen, E. M., Heupel, M. R., \& Moland, E. (2012). Three-dimensional kernel utilization distributions improve estimates of space use in aquatic animals. Canadian Journal of Fisheries and Aquatic Sciences, 69, 565-572. doi:10.1139/F2011179

Stillfried, M., Belant, J. L., Svoboda, N. J., Beyer, D. E., \& Kramer-Schadt, S. (2015). When top predators become prey: Black bears alter movement behaviour in response to hunting pressure. Behavioural Processes, 120, 30-39. doi:10.1016/j.beproc.2015.08.003

Swart, S., \& Speich, J. (2010). An altimetry-based gravest empirical mode south of Africa: 2. Dynamic nature of the Antarctic Circumpolar Current fronts. Journal of Geophysical Research, 115.

Switzer, P. V. (1993). Site fidelity in predictable and unpredictable habitats. Evolutionary Ecology, 7, 533-555.

Tosh, C. A., de Bruyn, P. J. N., Steyn, J., Bornemann, H., van den Hoff, J., Stewart, B. S., .. Bester, M. N. (2015). The importance of seasonal sea surface height anomalies for 
foraging juvenile southern elephant seals. Marine Biology, 162(10), 2131-2140. doi:10.1007/s00227-015-2743-4

Tosh, C. A., Steyn, J., Bornemann, H., van den Hoff, J., Stewart, B., Plötz, J., \& Bester, M. (2012). Marine habitats of juvenile southern elephant seals from Marion Island. Aquatic Biology, 17(1), 71-79. doi:10.3354/ab00463

Tracey, J. A., Sheppard, J., Zhu, J., Wei, F., Swaisgood, R. R., \& Fisher, R. N. (2014). Movement-Based estimation and visualization of space use in 3D for wildlife ecology and conservation. PLOS ONE, 9(7), e101205. doi:10.1371/journal.pone.0101205

Vander Zanden, H. B., Bolten, A. B., Tucker, A. D., Hart, K. M., Lamont, M. M., Fujisaki, I., ... Bjorndal, K. A. (2016). Biomarkers reveal sea turtles remained in oiled areas following the Deepwater Horizon oil spill. Ecological Applications, 26(7), 2145-2155. doi:10.1002/eap.1366

Vardanis, Y., Nilsson, J.-Å., Klaassen, R. H. G., Strandberg, R. \& Alerstam, T. (2016) Consistency in long-distance bird migration: contrasting patterns in time and space for two raptors. Animal Behaviour, 113, 177-187.

Vermeulen, E., Balbiano, A., Belenguer, F., Colombil, D., Failla, M., Intrieri, E., \& Bräger, S. (2016). Site-fidelity and movement patterns of bottlenose dolphins ( Tursiops truncatus ) in central Argentina : essential information for effective conservation. Aquatic Conservation: Marine and Freshwater Ecosystems, (January 2015). doi:10.1002/aqc.2618

Wakefield, E. D., Cleasby, I. R., Bearhop, S., Bodey, T. W., Davies, R. D., Miller, P. I., ... Hamer, K. C. (2015). Long-term individual foraging site fidelity — why some gannets don' t change their spots. Ecology, 96(11), 3058-3074.

Ward, J. H. J. (1963). Hierarchical grouping to optimize an objective function. Journal of the American Statistical Association, 58(301), 236-244. 
Weber, N., Duengkae, P., Fahr, J., Dechmann, D. K. N., Phengsakul, P., Khumbucha, W., ... Newman, S. (2015). High-resolution GPS tracking of Lyle's flying fox between temples and orchards in central Thailand. The Journal of Wildlife Management, 79(6), 957-968. doi:10.1002/jwmg.904

Wege, M., Tosh, C. A., de Bruyn, P. J. N., \& Bester, M. N. (2016). Cross-seasonal foraging site fidelity of subantarctic fur seals: implications for marine conservation areas. Marine Ecology Progress Series, 554, 225-239. doi:10.3354/meps11798

Whisson, D. A., Dixon, V., Taylor, M. L., \& Melzer, A. (2016). Failure to respond to food resource decline has catastrophic consequences for koalas in a high-density population in southern Australia. PLoS ONE, 11(1), 1-12. doi:10.1371/journal.pone.0144348

Wolak, M. E., Fairbairn, D. J., \& Paulsen, Y. R. (2012). Guidelines for estimating repeatability. Methods in Ecology and Evolution, 3, 129-137. doi:10.1111/j.2041210X.2011.00125.X 
593 Table 1: Elephant seals tracked over multiple migrations.

\begin{tabular}{lllllll}
\hline Tag & Sex & $\boldsymbol{N} \begin{array}{l}\text { Age at } \\
\text { deployments }\end{array}$ & $\begin{array}{l}\text { Years successfully } \\
\text { tracked }\end{array}$ & $\begin{array}{l}\text { Inter-annual UD } \\
\text { overlap }\end{array}$ & $\begin{array}{l}\text { Multi-year UD } \\
\text { overlap }\end{array}$ \\
\hline GG335 & $F$ & 6 & $7,8,9,10,11,12$ & $\begin{array}{l}2007,2008,2009,2010,2011, \\
2012\end{array}$ & $0.65 \pm 0.17$ & $0.57 \pm 0.15$ \\
O0021 & F & 3 & $5,6,7$ & $2007,2008,2009$ & $0.91 \pm 0.03$ & 0.92 \\
O0052 & M & 5 & $4,5,6,9,11$ & $2006,2007,2008,2011,2013$ & $0.74 \pm 0.09$ & $0.64 \pm 0.19$ \\
P0043 & F & 3 & $8,9,10$ & $2007,2008,2009$ & $0.69 \pm 0.13$ & 0.48 \\
P0225 & M & 2 & 8,12 & 2007,2011 & - & 0.74 \\
RR217 & F & 2 & 4,6 & 2009,2011 & - & 0.31 \\
WW061 & F & 4 & $7,10,11,12$ & $2008,2011,2012,2013$ & $0.87 \pm 0.09$ & $0.58 \pm 0.19$ \\
YY039 & F & 2 & 4,7 & 2008,2011 & - & 0.19 \\
YY189 & F & 7 & $2,3,4,5,6,8,9$ & $2006,2007,2008,2009,2010$, & $0.71 \pm 0.09$ & $0.64 \pm 0.19$ \\
\hline
\end{tabular}

594 Mean $( \pm$ SD) overlap in inter-annual utilization distributions, as well as mean $( \pm$ SD) overlap 595 in multiple-year utilization distributions, are reported. Only tracks over periods of more than 59630 days (median: 223, range: 38 - 292) were included. 
598 Table 2: Inter-annual and multi-year overlap in 95\% and 50\% three-dimensional utilization

599 distributions (3D-UDs) for southern elephant seals.

\section{5\% 3D-UD}

\begin{tabular}{|c|c|c|c|c|c|}
\hline \multirow[b]{2}{*}{ Tag } & \multirow[b]{2}{*}{$N$} & \multicolumn{2}{|l|}{ Inter-annual } & \multicolumn{2}{|l|}{ Multi-year } \\
\hline & & Day & Night & Day & Night \\
\hline GG335 & 6 & $0.43 \pm 0.1$ & $0.51 \pm 0.15$ & $0.41 \pm 0.15$ & $0.48 \pm 0.11$ \\
\hline 00021 & 3 & $0.56 \pm 0.09$ & $0.58 \pm 0.14$ & 0.38 & 0.5 \\
\hline 00052 & 5 & $0.66 \pm 0.2$ & $0.63 \pm 0.24$ & $0.47 \pm 0.16$ & $0.45 \pm 0.13$ \\
\hline PO043 & 3 & 0.71 & 0.71 & - & - \\
\hline PO225 & 2 & - & - & 0.3 & 0.29 \\
\hline RR217 & 2 & - & - & 0.23 & 0.25 \\
\hline WW061 & 4 & 0.56 & 0.66 & $0.28 \pm 0.07$ & $0.35 \pm 0.01$ \\
\hline YY039 & 2 & - & - & 0.09 & 0.04 \\
\hline \multirow[t]{3}{*}{ YY189 } & 7 & $0.61 \pm 0.14$ & $0.62 \pm 0.11$ & $0.51 \pm 0.17$ & $0.52 \pm 0.15$ \\
\hline & & $0.54 \pm 0.15$ & $0.57 \pm 0.15$ & $0.45 \pm 0.17$ & $0.47 \pm 0.15$ \\
\hline & & $\underline{50 \% 3 D-U D}$ & & & \\
\hline GG335 & 6 & $0.12 \pm 0.07$ & $0.25 \pm 0.22$ & $0.14 \pm 0.17$ & $0.19 \pm 0.15$ \\
\hline 00021 & 3 & $0.38 \pm 0.05$ & $0.44 \pm 0.02$ & 0.21 & 0.26 \\
\hline 00052 & 5 & $0.57 \pm 0.04$ & $0.62 \pm 0.41$ & $0.29 \pm 0.31$ & $0.24 \pm 0.27$ \\
\hline PO043 & 3 & 0.62 & 0.62 & - & - \\
\hline PO225 & 2 & - & - & 0.07 & 0.08 \\
\hline RR217 & 2 & - & - & 0 & 0 \\
\hline WW061 & 4 & 0.22 & 0.56 & $0.02 \pm 0.03$ & 0 \\
\hline YY039 & 2 & - & - & 0 & 0 \\
\hline \multirow[t]{2}{*}{ YY189 } & 7 & $0.37 \pm 0.22$ & $0.44 \pm 0.14$ & $0.22 \pm 0.2$ & $0.3 \pm 0.19$ \\
\hline & & $0.31 \pm 0.21$ & $0.39 \pm 0.23$ & $0.2 \pm 0.22$ & $0.22 \pm 0.2$ \\
\hline
\end{tabular}


601 Table 3: Repeatability ( $r$ ) values of habitat use parameters.

\section{Parameter}

Daytime 95\% 3D UD (kernel volume)

Night-time 95\% 3D UD (kernel volume)

Daytime 50\% 3D UD (kernel volume)

Night-time 50\% 3D UD (kernel volume)

Maximum distance travelled from MI

Bearing of maximum distance point from MI
Repeatability ( $r$ )

0.62

0.60

0.61

0.67

0.62

0.53

602

Repeatability $(r)$ values were calculated from intra-class correlation coefficients.

603

604 
Figure 1: Post-moult track locations for nine southern elephant seals tracked over multiple years. The grey-shaded polygon represents the overlap between the $95 \%$ kernel density utilization distributions for all tracks.

611 Figure 2: Three-dimensional kernel density utilization distributions (3D-UDs) over multiple years for five southern elephant seals. Darker shading indicates 50\% 3D-UDs and lighter shading 95\% 3D-UDs.

614

Figure 3: Hierarchical cluster analysis of migration strategies of southern elephant seals tracked over multiple post-moult migrations, illustrating the three identified behavioural clusters (C1-C3). Locations of migrations identified in each of the clusters are presented in the three maps. Positions of all track locations not within a particular cluster are illustrated in

619 light grey. PO225 is represented in only one migration, due to a comparatively low number of recorded daytime dive depths in 2007. STF $=$ Subtropical Front, SAF $=$ Subantarctic Front, APF $=$ Antarctic Polar Front. Frontal locations were determined from Swart \& Speich (2010). 


\section{Introduction}

2 Many species display foraging site fidelity, returning repeatedly to the same foraging areas

3 (e.g. Augé, Chilvers, Moore, \& Davis, 2014; Weber et al., 2015), even when habitat quality is 4 sub-optimal (Krebs, 1971; Merkle, Cherry, \& Fortin, 2015). Fidelity to foraging areas may

5 have long-term advantages for individual fitness, particularly in unpredictable environments

6 (Switzer, 1993). For example, animals may return to foraging areas because they are familiar

7 with resources (Greenwood, 1980) and able to exploit comparatively productive areas,

8 resulting in long-term energetic gains. Animals may also return to certain areas because they

9 are familiar with potential refuges and able to avoid predation (Clarke et al., 1993; Forrester,

10 Casady, \& Wittmer, 2015). The benefits of long-term site fidelity may have short-term costs

11 if sufficient food cannot be found in temporally heterogeneous environments (Bradshaw,

12 Hindell, Sumner, \& Michael, 2004). More significant fitness costs of site fidelity may be incurred when animals are unable to respond to short- and medium term changes in food availability by switching between foraging patches (e.g. Newell, 1999; Whisson, Dixon, Taylor, \& Melzer, 2016). Once an individual has learned a behaviour it may be hesitant to change or to adopt new foraging strategies, especially if the associated risks are great. The risks of looking for new foraging patches may be particularly great if foraging patches are far apart or are of unpredictable quality. Individual animals sometimes display individual-level foraging fidelity, where the intra-individual variation in space use is less than the inter-individual variation in space use within a population (Wakefield et al., 2015). Individual-level foraging fidelity may be a type of individual specialization, best explained by phenotypic trade-offs when specialization in one strategy results in the inability to efficiently perform an alternative strategy (Bolnick et al., 2003). Various foraging behaviours such as prey recognition, capture ability, digestive 
capacity and predator avoidance strategies may be affected. The existence of individual-level specialization, in terms of site fidelity and dietary specialization, has long been recognized but rarely explicitly considered in ecological studies (Piper, 2011).

Foraging site fidelity has been widely illustrated in marine vertebrates, including marine birds (e.g. Baylis et al., 2015), turtles (e.g. Carman et al., 2016), fish (e.g. Gannon et al., 2015) and marine mammals (e.g. Vermeulen et al., 2016). Pinnipeds in particular often display high levels of foraging site fidelity (e.g. Arthur et al., 2015; Baylis et al., 2015; Wege, Tosh, de Bruyn, \& Bester, 2016). Fidelity to large-scale foraging areas was demonstrated for southern elephant seals (Mirounga leonina), but individual seals that were faithful to foraging areas did not show mass gain benefits (Bradshaw et al., 2004). However, it was proposed that returning to generally more productive areas could result in benefits over longer timescales (Bradshaw et al., 2004). Also, Authier et al. (2012) illustrated that lower variation in the isotopic foraging niche of male southern elephant seals covaried positively with estimated lifespans, thereby suggesting lifetime fitness benefits associated with foraging fidelity in this species. While these reports provide valuable insights, little information is available regarding the foraging area fidelity of individual elephant seals over the long term (3+ years) and no information exists on fidelity to specific foraging strategies used to exploit the vertical dimension.

Animal space use is typically quantified in two dimensions, despite the fact that most animals also use space in a vertical dimension (i.e. by flying, diving or burrowing). Incorporating the vertical component into representations of space use may provide novel ecological insights and have conservation management benefits (Tracey et al., 2014). Habitat use studies have attempted to incorporate the vertical dimension through separate analyses of 
vertical metrics without incorporating spatial position (2-dimensions). Some recent studies, particularly on marine predators, have incorporated the vertical behaviour component (e.g. spherical first-passage time, Bailleul, Lesage, \& Hammill, 2010). More recently, three dimensional utilization distributions (3D UDs) quantified vertical space use and home range overlap of sharks (Simpfendorfer, Olsen, Heupel, \& Moland, 2012) and birds (Cooper, Sherry, \& Marra, 2014).

Southern elephant seals have a circumpolar distribution and their foraging behaviour is closely linked to their specific haul-out sites (Hindell et al., 2016). Elephant seals display a high degree of fidelity to their haul-out sites (Hofmeyr, Kirkman, Pistorius, \& Bester, 2012), which may be an important indication of learned behaviour in these animals. Here we assess (1) the persistence of migration site fidelity in southern elephant seals; (2) fidelity to a threedimensional environment, particularly the water depths exploited; and (3) the individual repeatability and specialization of migration strategies. We predicted that foraging site fidelity in elephant seals would decay over the long-term, due to the spatiotemporally patchy nature of their prey distribution (i.e. that site fidelity would persist only as long as prey patches persist - Kamil, 1983). Fidelity to three-dimensional environments was expected to be lower, both as a result of variation in the vertical distribution of prey items, as well as the influences of physiological development and ageing on the dive capacity of seals. Finally, the propensity for Marion Island's elephant seals to forage in deep ocean areas, south-west of the island (Hindell et al., 2016; Oosthuizen, Bester, Altwegg, McIntyre, \& de Bruyn, 2015) led to a prediction of limited individual-level specialization in migration strategies.

\section{Methods}


The research described refers to an Antarctic seal species, the southern elephant seal. It conforms to Antarctic Treaty legislation and to the SCAR Code of Conduct for the Use of Animals for Scientific Purposes in Antarctica (ATCM XXXIV 2011). We adhere to the 'Guidelines for the use of animals in research' as published in Animal Behaviour (1990, 41, 183-186) and the laws of the country where the research was conducted. All flipper tagging and satellite device deployment/retrieval procedures were reviewed and approved by the Animal Use and Care Committee and more recently the renamed Animal Ethics Committee of the University of Pretoria (AUCC 040827-024; AUCC 040827-023 and EC077-15), and fieldwork was performed under Prince Edward Island's Research Permits R8-04 and R04-08. All dive and track data are available via the PANGAEA Data Publisher for Earth \& Environmental Science (doi:10.1594/PANGAEA.871448).

Track data and filtering

As part of a series of tracking projects between April 2004 and February 2013, we deployed 95 satellite-relay data loggers (either Series 9000 SRDLs, or CTD-SRDLs, Sea Mammal Research Unit, University of St Andrews, Scotland) on southern elephant seals of both sexes hauled out at sub-Antarctic Marion Island ( $\left.46^{\circ} 54^{\prime} \mathrm{S} ; 37^{\circ} 45^{\prime} \mathrm{E}\right)$. These instruments provided track locations (obtained via Service Argos estimates), basic time-depth profiles of approximately 20 dives per day and a maximum of four temperature-depth profiles per day

95 (Boehme et al., 2009).

96

Uniquely marked (de Bruyn, Tosh, Oosthuizen, Phalanndwa, \& Bester, 2008) seals were immobilized using a handheld syringe, extended by a length of drip-tubing, to deliver a calculated dose of ketamine based on a visual estimation of the seal's mass (Bester, 1988).

100 Seals were then observed from a distance until the anticipated end of the induction period 
101 (about 20 min post-injection), and then approached for the first time to assess the depth of anaesthesia by evaluating reactions to stimuli (e.g. slight noise and touch) (Bornemann et al., 2013). As soon as the seals tolerated physical stimuli, their eyes were covered with a towel to

104 protect against solar radiation and minimise unnecessary stimuli. Transmitters were glued

105 onto the fur of the heads of the seals using a quick-setting epoxy resin (Field et al., 2012).

106 The heaviest of these devices (CTD-SRDLs) weighed $545 \mathrm{~g}$, representing $0.19 \%$ of the average post-moult departure mass of female elephant seals from this population (Postma, Bester, \& De Bruyn, 2013). After their post-migration return to the island, data transmitting devices were either removed from sedated animals by shaving them off the fur or shed

110 naturally with the pelage during the annual moult. No short-term deleterious effects were 111 evident with immobilization, device deployment or retrieval, while tracking devices attached 112 to elephant seals are known not to affect individual mass gain or survival in the long term

113 (McMahon, Field, Bradshaw, White, \& Hindell, 2008). We report on a subset of the resultant 114 dataset, after retaining data from 34 post-moult migrations (as opposed to post-breeding 115 migrations, Le Boeuf \& Laws, 1994) from nine individual seals (two males and seven 116 females) that successfully carried instruments over multiple winter migrations (Table 1). 117 Only tracks with data for a minimum period of 30 days were included. Seals in this sample 118 provided tracking and dive data for a median of three migrations (range: $2-7$ ), each 119 migration covering a median period of 223 days (range: 38 - 292). All statistical analyses were undertaken in the R programming environment (Team, 2016). Track data were filtered to remove estimated locations that required swim speeds in excess of $3.5 \mathrm{~m} / \mathrm{s}$ and/or creating spikes in the track with angles smaller than $15^{\circ}$ and $25^{\circ}$

124 with extensions greater than 2,500 m and 5,000 m, respectively (Freitas, Lydersen, Fedak, \& 125 Kovacs, 2008). 
Inter-annual and multi-year fidelity

128 Fidelity to home ranges was expressed as the overlap in 95\% kernel density utilization

129 distributions (UD) of two dimensional location data (latitude and longitude) and three

130 dimensional diving data (latitude, longitude and dive depth). The two dimensional UDs were

131 calculated using an ad hoc smoothing parameter, which assumes a bivariate normal UD in the

132 R package 'adehabitatHR' (Calenge, 2015). Overlap of two-dimensional UDs was calculated

133 following Arthur et al. (Arthur et al., 2015), using Bhattacharyya's affinity (BA) for a general

134 measure of similarity between UD estimates.

135

Daily median dive depth values were calculated for each two dimensional location to create a three dimensional dataset. We divided the datasets into daytime and nocturnal dives, as southern elephant seals often display diel vertical migration (e.g. Biuw et al., 2010; McIntyre, Bornemann, Plötz, Tosh, \& Bester, 2011). Three dimensional kernel density

140 utilisation distributions (3D-UD) were estimated in the ' $k s$ ' package (Duong, 2016), using a 141 two-stage plug-in method, developed by Duong and Hazelton (2003) and applied by

142 Simpfendorfer et al. (2012) and Cooper et al. (2014) amongst others. We calculated overlap in 95\% 3D-UDs both inter-annually and over multiple years (multi-year) for individual seals,

144 following Simpfendorfer et al. (2012). Inter-annual overlap is the overlap for tracks from

145 consecutive years (e.g. overlap between 2006 and 2007; 2007 and 2008 etc.), while multi-

146 year overlap was calculated between tracks separated by a year or more (e.g. overlap between 1472006 and 2008; 2006 and 2009 etc.). 
150 We applied a repeatability statistic to a series of track and behavioural metrics to assess

151 individual behavioural consistency compared to the behaviours displayed by all the seals in

152 the dataset. This repeatability statistic was calculated, making use of an intra-class correlation

153 coefficient (Wolak, Fairbairn, \& Paulsen, 2012), following McFarlane Tranquila et al.

154 (2014). Accordingly, among-groups variance $\left(s_{A}^{2}\right)$ and within-individual variance components $\left(s^{2}\right)$ are derived from a linear mixed-effects model (R package 'psychometric').

156 Repeatability $(r)$ was then calculated as:

$$
r=\frac{s_{A}^{2}}{\left(s^{2}+s_{A}^{2}\right)}
$$

157 where high $r$ values (>0.5) indicate consistent individual behaviours.

The repeatability statistic was applied to the following track and behavioural metrics: (1) the daytime and nocturnal 95\% and 50\% 3D-UDs incorporating the dive depths of tracked seals; (2) the maximum distance travelled away from Marion Island per migration and (3) the bearing of the location at the maximum distance away from Marion Island.

Hierarchical clustering

165 We explored the possibility of individually specific migration strategies (consistent long term behaviour) using a hierarchical clustering approach. A principal components analysis (PCA) was first applied to a series of track- and dive metrics to generate a single metric representative of an overall strategy. Six daily metrics were included in the PCA: (1) median daytime dive depth; (2) median night-time dive depth; (3) diel vertical migration (defined as the difference between daytime and night-time median dive depths); (4) distance from

171 Marion Island; (5) bearing from Marion Island; and (6) mean speed of travel (mean speed of travel between all locations associated with a specific day). The first five principal components explained $93.7 \%$ of the variance. The relative contribution of each principal 
174 component to a single, weighted metric was determined from the loadings of the PCA output.

175 This value was used in a hierarchical clustering analysis, using Ward's clustering criterion

176 (Ward, 1963) on a Euclidean distance matrix.

\section{$178 \quad$ Results}

179 Home range overlap

180 Seven of the nine seals tracked over multiple migrations had overlapping 95\% UDs that

181 encompassed more than 50\% of their home ranges (UD overlap > 0.5) (Fig. 1). Two

182 individual seals tracked twice in non-consecutive years (RR217:2009, 2011 and

183 YY039:2008, 2011), had comparatively disparate UDs, characterised by small areas of 184 overlap (0.31 and 0.19 respectively, Table 1). Mean inter-annual overlap of 95\% UDs was $1850.73 \pm 0.14$ (Table 1). Overlap of UDs for multi-year periods were slightly lower at $0.61 \pm$ 186 0.18. Inter-annual overlap of 95\% UDs was consistently high for individuals tracked over 187 consecutive migrations, with a minimum overlap of $0.65 \pm 0.17$ (maximum of $0.91 \pm 0.03$ ).

188 Multi-year overlap was more variable, ranging from 0.19 to 0.92 (Table 1).

Three-dimensional UD overlap

191 The mean inter-annual overlap of $95 \%$ 3D-UDs was $0.54 \pm 0.15$ for daytime dives and $0.57 \pm$

1920.15 for nocturnal dives. Overlap was slightly lower for multi-year periods at $0.45 \pm 0.17$ for 193 daytime dives and $0.47 \pm 0.15$ for nocturnal dives. Five of the six seals that were tracked in 194 consecutive years, recorded 95\% 3D-UDs that overlapped by $60 \%-71 \%$. Individual 195 variation was evident, with some seals using very similar three-dimensional spaces over long 196 time periods (e.g. YY189, Fig. 2, Table 2), while others used slightly different depths

197 between years (e.g. GG335, Fig. 2, Table 2) and others used completely different depths (e.g. 198 PO225, Fig. 2, Table) despite substantial overlap in the two dimensional 95\% UD (Fig. 1). 
199 Areas of restricted movement or 50\% 3D-UDs overlapped much less and was more variable between seals (Table 2), although two seals (PO043 and OO052) had similar areas of restricted movement and diving behaviours in consecutive years $(50 \% 3 \mathrm{D}$-UDs overlap $=$ approximately $60 \%)$.

Two seals (PO225 and GG335) used similar oceanographic areas (2-D UD) (Fig. 1) but had very different diving behaviours (3-D -UD) (Fig. 2) in their subsequent migrations. GG335 dived to varied depths but maintained a substantial overlap in 3D-UDs over the 5 years that it was tracked. This seal employed two general diving strategies, performing deeper dives in the last two migrations $(2011,2012)$, compared to the preceding three years (Fig. 2). PO225 dived to variable depths during its 2007 migration but used more specific depth layers in 2011.

\section{Repeatability}

213 All repeatability ( $r$ ) values were larger than 0.5 (Table 3), suggesting consistency in 214 individual behaviours. The lowest value (0.53) was calculated for track bearings of the point 215 furthest away from Marion Island, indicating least consistency for this metric. All other $r$ 216 values were equal to or larger than 0.6 (Table 3), indicating high levels of consistency in the

217 three-dimensional area sizes used by seals and distances travelled away from Marion Island.

219 Hierarchical clustering

220 Five principal components (PCs) explained $93.7 \%$ of the variance in our dataset and included

221 both horizontal movement and vertical dive behaviour metrics. PC1 was most strongly

222 associated with DVM, PC2 with distance and bearing from Marion Island + night-time dive 
depths, PC3 with daytime dive depths, PC4 with travel speed and PC5 with bearing and distance.

Hierarchical clustering revealed three distinct migration strategies used by the tracked seals (Fig. 3), and multiple tracks of individual seals tended to group together in the same clusters (e.g. O0052, GG335). Two individuals (WW061 and RR217) grouped in two different clusters. Seals grouping into specific clusters generally foraged in the same areas. For example, GG335 (2007) and WW061 (2008) both travelled in a westerly direction away from Marion Island (and further), compared to their other migrations (Fig. 1). These migrations clustered with all of the migrations recorded for OO021 (Fig. 3), which used a similar spatial area (Fig. 1).

Migrations in cluster $1(\mathrm{C} 1)$ covered a wide latitudinal range, from the Subtropical Front in the north to south of the APF (Fig. 3). Migrations in cluster 3 (C3) were characterised by the greatest distances away from Marion Island, but restricted to latitudes south of the Subantarctic Front, with many of the tracks concentrated south of the Antarctic Polar Front (APF). Cluster two (C2) comprised of tracks from one seal (OO052), which used a small area adjacent to Marion Island during all five of its post-moult migrations.

\section{Discussion}

243 Studies of fidelity to migration strategies over long-distances and long time periods, are often restricted to few migrations (e.g. two or three) (Mingozzi, Mencacci, Cerritelli, Giunchi, \& Luschi, 2016), although a few recent studies have successfully tracked seasonally migrating birds over multiple years (e.g. Berthold et al., 2002; Lopez-Lopez et al., 2014; Vardanis,

247 Nilsson, Klaassen, Strandberg \& Alerstam, 2016). Similarly, individual foraging site fidelity 
248 in elephant seals has only been studied from a small number of migrations, not separated by

249 more than one or two years (e.g. Bradshaw et al., 2004; Simmons, 2008). In one study, a

250 single northern elephant seal, M. angustirostris, followed the same path in 2006 as it did 11

251 years previously in 1995; although the North American continent predisposes migration by

252 this species to a westerly bearing away from haulout sites (Costa, Breed, \& Robinson, 2012).

253 Our study followed a small number of individual seals and reports on continued fidelity over

254 long distances and time periods not reported before. Seals tracked in our sample showed high

255 overlap in $95 \%$ UDs, even over extended periods of up to seven years - averaging more than

$25660 \%$ for both consecutive and non-consecutive migrations (Table 1). The long-term fidelity

257 to oceanographic areas used by seals included their use of the vertical environment, and

258 overlap in 95\% 3D-UDs averaged more than $45 \%$ over multi-year comparisons and more

259 than $50 \%$ for consecutive years.

260

Individual-level flexibility in inter-annual migration routes has been illustrated for

262 some migrating birds known to forage on prey items that are variably distributed (Vardanis,

263 Nilsson, Klaassen, Strandberg \& Alerstam, 2016), although the drivers of such flexibility

264 remain unknown. Bradshaw at al. (2004) were unable to link foraging success of tracked

southern elephant seals to the likelihood that they would alter their foraging strategies,

266

suggesting that elephant seals do not follow the win-stay/lose-switch rule (Shields, Cook,

267 Hebblethwaite, \& Wiles-Ehmann, 1988) over shorter time periods. Alternatively, they

268 suggested that elephant seals would benefit over longer periods by returning to areas with

269 generally increased productivity. While the condition of seals tracked in our sample is

270 unknown and we were unable to assess the impacts of migration strategies, the long-term

271 fidelity to migration patterns and oceanographic areas apparently supports the hypothesis of

272 Bradshaw et al. (2004) that the win-stay/lose-switch rule does not apply over multiple 
273 migrations in elephant seals. However, the reasonably small sample size we report on here 274 does not exclude the possibility that tracked seals rarely encountered such poor foraging success as to prompt any switches in strategy.

Two seals in our sample (PO225 and GG335) displayed much more overlap in their 2D UDs, compared to their 3-D UDs (Figs. 1 and 2). GG335 evidently switched its depth use strategy once between 2010 and 2011, performing deeper dives in 2011 and 2012 when compared to the earlier tracks. The two migrations of PO225 $(2007 ; 2011)$ were 3 years apart, limiting any hypotheses on the development of dive behaviour. However, it is unlikely that the observed differences in diving behaviour are due to ontogenic development of diving capacity (Bennett, McConnell, \& Fedak, 2001), because this seal was first tracked as an adult, eight year old male and diving capacity does not develop substantially once a seal reaches maturity (Grundling, 2014). Elephant seal dive strategies may change withinmigrations (e.g. Bester, Bornemann, \& McIntyre, in press; Biuw et al., 2010; McIntyre, Ansorge, et al., 2011), indicating that elephant seals are often able to exploit localised prey patches at different depths. The dissimilar diving behaviour seen in different migrations of PO225 and GG335 further suggests an element of inter-annual plasticity in foraging strategies. Long-term longitudinal tracking investigations are needed to explore these shifts in

291 diving strategies. Seal behaviours in our study showed high levels of individual repeatability $(r)$.

294 Combined with the outputs of the clustering exercise, these results suggest a high level of individual specialization in migration behaviour. Individual variation in southern elephant seal behaviours, and other marine predators, has been acknowledged and recently accounted

297 for in behavioural modelling exercises (e.g. Farnsworth et al., 2015; Massie et al., 2016; 
298 Stillfried, Belant, Svoboda, Beyer, \& Kramer-Schadt, 2015). Moreover, recent studies have

299 illustrated consistency and specialization in individual behaviour (e.g. Wakefield et al.,

300 2015). Southern elephant seals employ various foraging strategies, exploiting shallow water

301 masses associated with the Kerguelen Plateau, and the Antarctic Peninsula, or using deep,

302 open water regions in the Southern Ocean (Hindell et al., 2016). Female elephant seals in the

303 Antarctic Peninsula region display individual behavioural and foraging niche specialization

304 with substantial within-migration behavioural plasticity (Hückstädt et al., 2012). Similarly,

305 Marion Island elephant seals use three broad migration strategies (clusters) (Fig. 3), which

306 were identified from diel vertical migration patterns, dive depths, and distance and bearing

307 from Marion Island.

308

309

Implication of long-term fidelity and individual specialization

310 The Southern Ocean is rapidly changing with a generally warming and freshening trend

311 leading to expected poleward shifts in the distribution of lower trophic level consumers

312 (Constable et al., 2014). The long-term spatial fidelity of elephant seals, including three-

313 dimensional environments (this study), has potential implications for our understanding of

314 their behavioural response to disturbance. The origin of fidelity described here is unknown

315 and is not analysed in detail. However, site familiarity and fidelity may develop if juvenile

316 elephant seals are successful during their first foraging migration (Bradshaw et al., 2004).

317 This would suggest that environmental conditions experienced in early migrations may have

318 consequences for future migration strategies (Dall, Bell, Bolnick, \& Ratnieks, 2012). Juvenile

319 southern elephant seals tracked from Marion Island generally travel due west, irrespective of

320 year, and focus their foraging behaviour along bathymetric features, frontal zones and meso-

321 scale eddies (Tosh et al., 2012; 2015), adding to their familiarity of the surrounding ocean.

322 While the intra-migration dive behaviour of southern elephant seals is known to respond to 
323 changes in the temperature structure of the water column and associated changes in the

324 distribution of potential prey items (Guinet et al., 2014; McIntyre, Ansorge, et al., 2011), the

325 long-term fidelity to foraging areas and diving behaviour may limit coarser-scale movement

326 and behavioural adaptations of individual elephant seals to rapid environmental changes,

327 although this requires further investigation. Similarly, other taxa such as seabirds and marine

328 turtles, which rely on site-specific information gained early in life, may be more vulnerable to

329 rapid environmental change and other anthropogenic disturbances (Hipfner, 2008; Vander

330 Zanden et al., 2016; Wakefield et al., 2015). Future research needs to elucidate the role of

331 long-term behavioural adaptations in individual elephant seals in response to rapid

332 environmental change, particularly through long-term longitudinal monitoring of fitness

333 consequences associated with behavioural changes in relation to environmental differences.

Our results show the value of long-term data on known individuals for illustrating individual repeatability, and potentially specialization, in the migration strategies of animals.

Tracking studies are often used for conservation planning and environmental management purposes (e.g. Jabour et al., 2016). Such studies can benefit from incorporating seasonal variation in habitat use of target species (Braham et al., 2015), as well as samples representing substantial spatial variation (Mazor, Beger, Mcgowan, Possingham, \& Kark, 2016). However, while the influence of individual differences on our understanding of animal ecology is recognised (Dall et al., 2012), it is seldom implemented in population-level studies. Bolnick et al (2011) highlights that individual specialisation or phenotypic expression can have serious implications for studies on the ecology, evolution and conservation of

345 populations. For example, resource selection models which assume foragers are informed

346 about their total surroundings to select the most favourable areas would benefit from

347 incorporating effects associated with individual familiarity and fidelity (Wakefield et al., 
348 2015). Our study provides further support to the call for long-term longitudinal research

349 quantifying the influence of site familiarity, site fidelity and resource specialization on animal 350 population dynamics.

351

352

353 


\section{References}

Arthur, B., Hindell, M., Bester, M., Trathan, P., Jonsen, I., Staniland, I., ... Lea, M.-A. (2015). Return customers: foraging site fidelity and the effect of environmental variability in wide-ranging Antarctic fur seals. Plos One, 10, e0120888. doi:10.1371/journal.pone.0120888

ATCM (2011) SCAR's Code of Conduct for the Use of Animals for Scientific Purposes in Antarctica. IP53, Agenda Item CEP 8c, presented by SCAR during XXXIV Antarctic Treaty Consultative Meeting, Buenos Aires, Argentina, 20 June - 21 July 2011, 4pp. http://www.scar.org/scar_media/documents/science/atcm34_ip053_CofC_Animals.pdf

Augé, A. A., Chilvers, B. L., Moore, A. B., \& Davis, L. S. (2014). Importance of studying foraging site fidelity for spatial conservation measures in a mobile predator. Animal Conservation, 17, 61-71. doi:10.1111/acv.12056

Authier, M., Bentaleb, I., Ponchon, A., Martin, C., \& Guinet, C. (2012). Foraging fidelity as a recipe for a long life: foraging strategy and longevity in male southern elephant seals. PloS One, 7(4), e32026. doi:10.1371/journal.pone.0032026

Bailleul, F., Lesage, V., \& Hammill, M. O. (2010). Spherical First Passage Time: A tool to investigate area-restricted search in three-dimensional movements. Ecological Modelling, 221, 1665-1673.

Baylis, A. M. M., Orben, R. A., Arnould, J. P. Y., Peters, K., Knox, T., Costa, D. P., \& Staniland, I. J. (2015). Diving deeper into individual foraging specializations of a large marine predator, the southern sea lion. Oecologia, 179(4), 1053-1065. doi:10.1007/s00442-015-3421-4

Baylis, A. M. M., Orben, R. A., Pistorius, P., Brickle, P., Staniland, I., \& Ratcliffe, N. (2015). Winter foraging site fidelity of king penguins breeding at the Falkland Islands. Marine Biology, 162, 99-110. doi:10.1007/s00227-014-2561-0 
Bennett, K. A., McConnell, B. J., \& Fedak, M. (2001). Diurnal and seasonal variations in the duration and depth of the longest dives in southern elephant seals (Mirounga leonina): possible physiological and behavioural constraints. Journal of Experimental Biology, 204, 649-662.

Berthold, P., v. d. Bossche, W., Jakubiec, Z., Kaatz, C., Kaatz, M. \& Querner, U. (2002). Long-term satellite tracking sheds light upon variable migration strategies of White Storks (Ciconia ciconia). Journal of Ornithology, 143, 489-495.

Bester, M. N. (1988). Marking and monitoring studies of the Kerguelen stock of southern elephant seals Mirounga leonina and their bearing on biological research in the Vestfold Hills. Hydrobiologia, 165, 269-277.

Bester, M. N., Bornemann, H., \& McIntyre, T. (n.d.). Antarctic marine mammals and sea ice. In D. N. Thomas \& G. S. Dieckman (Eds.), Sea Ice (3rd ed.). Oxford: Wiley-Blackwell.

Biuw, M., Nøst, O. A., Stien, A., Zhou, Q., Lydersen, C., \& Kovacs, K. M. (2010). Effects of hydrographic variability on the spatial, seasonal and diel diving patterns of southern elephant seals in the eastern Weddell Sea. PLoS ONE, 5(11), e13816. doi:10.1371/journal.pone.0013816

Boehme, L., Lovell, P., Biuw, M., Roquet, F., Nicholson, J., Thorpe, S. E., ... Fedak, M. (2009). Technical Note: Animal-borne CTD-Satellite Relay Data Loggers for real-time oceanographic data collection. Ocean Science, 5, 685-695.

Bolnick, D. I., Amarasekare, P., Araujo, M. S., R, B., Levine, J. M., Novak, M., ... Vasseur, D. A. (2011). Why intraspecific trait variation matters in community ecology. Trends in Ecology and Evolution, 26(4), 183-192. doi:10.1016/j.tree.2011.01.009

Bolnick, D. I., Svanbäck, R., Fordyce, J. A., Yang, L. H., Davis, J. M., Hulsey, C. D., \& Forister, M. L. (2003). The ecology of individuals: incidence and implications of individual specialization. The American Naturalist, 161(1), 1-28. 
404 Bradshaw, C. J. A., Hindell, M. A., Sumner, M. D., \& Michael, K. J. (2004). Loyalty pays:

405

406

407

408

409

410

411

412

413

414

415

416

417

418

419

420

421

422

423

424

425

426

427

428 potential life history consequences of fidelity to marine foraging regions by southern elephant seals. Animal Behaviour, 68, 1349-1360.

Braham, M., Miller, T., Duerr, A. E., Lanzone, M., Fesnock, A., LaPre, L., ... Katzner, T. (2015). Home in the heat: Dramatic seasonal variation in home range of desert golden eagles informs management for renewable energy development. Biological Conservation, 186, 225-232. doi:10.1016/j.biocon.2015.03.020

Calenge, C. (2015). Home Range Estimation in R : the adehabitatHR Package. Retrieved from https://cran.r-project.org/web/packages/adehabitatHR/index.html

Carman, V. G., Bruno, I., Maxwell, S., Álvarez, K., Albareda, D., Acha, E. M., \& Campagna, C. (2016). Habitat use, site fidelity and conservation opportunities for juvenile loggerhead sea turtles in the Río de la Plata, Argentina. Marine Biology, 163. doi:10.1007/s00227-015-2795-5

Clarke, M. F., da Silva, K. B., Lair, H., Pocklington, R., Kramer, D. L., \& McLaughlin, R. L. (1993). Site familiarity affects escape behaviour of the eastern chipmunk, Tamias striatus. Oikos, 66(3), 533-537.

Constable, A. J., Melbourne-Thomas, J., Corney, S. P., Arrigo, K. R., Barbraud, C., Barnes, D. K. A., ... Ziegler, P. (2014). Climate change and Southern Ocean ecosystems I : how changes in physical habitats directly affect marine biota. Global Change Biology. doi: $10.1111 /$ gcb.12623

Cooper, N. W., Sherry, T. W., \& Marra, P. P. (2014). Modeling three-dimensional space use and overlap in birds. Auk, 131, 681-693. doi:10.1642/AUK-14-17.1

Costa, D. P., Breed, G. A., \& Robinson, P. W. (2012). New insights into pelagic migrations : implications for ecology and conservation. Annual Review of Ecology, Evolution, and Systematics, 43, 73-96. doi:10.1146/annurev-ecolsys-102710-145045 
430

Dall, S. R. X., Bell, A. M., Bolnick, D. I., \& Ratnieks, F. L. W. (2012). An evolutionary ecology of individual differences. Ecology Letters, 15, 1189-1198. doi:10.1111/j.14610248.2012.01846.x

de Bruyn, P. J. N., Tosh, C. A., Oosthuizen, W. C., Phalanndwa, M. V, \& Bester, M. N. (2008). Temporary marking of unweaned southern elephant seal (Mirounga leonina L.) pups. South African Journal of Wildlife Research, 38(2), 133-137.

Duong, T. (2016). Package “ks”. Retrieved from https://cran.rproject.org/web/packages/ks/index.html

Duong, T., \& Hazelton, M. (2003). Plug-in bandwidth matrices for bivariate kernel density estimation. Journal of Nonparametric Statistics, 15(1), 17-30. doi:10.1080/10485250306039

Farnsworth, M. L., Dickson, B. G., Zachmann, L. J., Hegeman, E. E., Cangelosi, A. R., Jackson, T. G. J., \& Scheib, A. F. (2015). Short-term space-use patterns of translocated Mojave desert tortoise in southern California. PLoS ONE, 10(9), e0134250. doi:10.1371/journal.pone.0134250

Field, I. C., Harcourt, R. G., Boehme, L., Bruyn, P. J. N. De, Charrassin, J.-B., McMahon, C. R., ... Hindell, M. a. (2012). Refining instrument attachment on phocid seals. Marine Mammal Science, 28(3), E325-E332. doi:10.1111/j.1748-7692.2011.00519.x

Forrester, T. D., Casady, D. S., \& Wittmer, H. U. (2015). Home sweet home: fitness consequences of site familiarity in female black-tailed deer. Behavioral Ecology and Sociobiology, 69, 603-612. doi:10.1007/s00265-014-1871-z

Freitas, C., Lydersen, C., Fedak, M., \& Kovacs, K. M. (2008). A simple new algorithm to filter marine mammal Argos locations. Marine Mammal Science, 24(2), 315-325.

Gannon, R., Payne, N. L., Suthers, I. M., Gray, C. A., Meulen, D. E. Van Der, \& Taylor, M. D. (2015). Fine-scale movements, site fidelity and habitat use of an estuarine dependent 
456

457

458

459

460

461

462

463

464

465

466

467

468

469

470

471

472

473

474

475

476

477

Greenwood, B. Y. P. J. (1980). Mating systems, philopatry and dispersal in birds and mammals. Animal Behaviour, 28, 1140-1162.

Grundling, A. (2014). Ontogeny of southern elephant seal ( Mirounga leonina) dive behaviour. B.Sc. hons. thesis, University of Pretoria.

Guinet, C., Vacquié-garcia, J., Picard, B., Bessigneul, G., Lebras, Y., Dragon, A. C., ... Bailleul, F. (2014). Southern elephant seal foraging success in relation to temperature and light conditions : insight into prey distribution. Marine Ecology Progress Series, 499, 285-301. doi:10.3354/meps 10660

Hindell, M. A., McMahon, C. R., Bester, M. N., Boehme, L., Costa, D., Fedak, M. A., ... Charrassin, J.-B. (2016). Circumpolar habitat use in the southern elephant seal: implications for foraging success and population trajectories. Ecosphers, 7(May), e01213. doi:10.1002/ ecs2.1213

Hipfner, J. M. (2008). Matches and mismatches: ocean climate, prey phenology and breeding success in a zooplanktivorous seabird. Marine Ecology Progress Series, 368, 295-304. doi:10.3354/meps07603

Hofmeyr, G. J. G., Kirkman, S. P., Pistorius, P. A., \& Bester, M. N. (2012). Natal site fidelity by breeding female southern elephant seals in relation to their history of participation in the winter haulout. African Journal of Marine Science, 34(3), 373-382.

Hückstädt, L. A., Koch, P. L., McDonald, B. I., Goebel, M. E., Crocker, D. E., \& Costa, D. P. (2012). Stable isotope analyses reveal individual variability in the trophic ecology of a top marine predator, the southern elephant seal. Oecologia, 169(2), 395-406. doi:10.1007/s00442-011-2202-y 
Jabour, J., Lea, M.-A., Goldsworthy, S. D., Melcher, G., Sykes, K., \& Hindell, M. A. (2016). Marine telemetry and the conservation and management of risk to seal species in Canada and Australia. Ocean Development \& International Law, 47(3), 255-271. doi:10.1080/00908320.2016.1194094

Kamil, A. C. (1983). Optimal foraging theory and the psychology of learning. American Zoologist, 23(2), 291-302.

Krebs, J. R. (1971). Territory and breeding density in the Great Tit, Parus Major L. Ecology, $52(1), 2-22$.

Le Boeuf, B. J., \& Laws, R. M. (1994). Elephant Seals: Population Ecology, Behavior, and Physiology. Berkeley: University of California Press. doi:http://ark.cdlib.org/ark:/13030/ft7b69p131/

López-López, P., García-Ripollés, C. \& Urios, V. (2014). Individual repeatability in timing and spatial flexibility of migration routes of trans-Saharan migratory raptors. Current Zoology, 60(5), 642-652.

Massie, P. P., McIntyre, T., Ryan, P. G., Bester, M. N., Bornemann, H., \& Ansorge, I. J. (2016). The role of eddies in the diving behaviour of female southern elephant seals. Polar Biology, 39, 297-307. doi:10.1007/s00300-015-1782-0

Mazor, T., Beger, M., Mcgowan, J., Possingham, H. P., \& Kark, S. (2016). The value of migration information for conservation prioritization of sea turtles in the Mediterranean. Global Ecology and Biogeography, 25, 540-552. doi:10.1111/geb.12434

McFarlane Tranquilla, L. A., Montevecchi, W. A., Fifield, D. A., Hedd, A., Gaston, A. J., Robertson, G. J., \& Phillips, R. A. (2014). Individual winter movement strategies in two species of Murre (Uria spp.) in the Northwest Atlantic. PLoS ONE, 9(4). doi:10.1371/journal.pone.0090583 
McIntyre, T., Ansorge, I. J., Bornemann, H., Plötz, J., Tosh, C. A., \& Bester, M. N. (2011).

503

504

505

506

507

508

509

510

511

512

513

514

515

516

517

518

519

520

521

522

523

524

525

526 Elephant seal dive behaviour is influenced by ocean temperature: implications for climate change impacts on an ocean predator. Marine Ecology Progress Series, 441, 257-272. doi:10.3354/meps09383

McIntyre, T., Bornemann, H., Plötz, J., Tosh, C. A., \& Bester, M. N. (2011). Water column use and forage strategies of female southern elephant seals from Marion Island. Marine Biology, 158(9), 2125-2139. doi:10.1007/s00227-011-1719-2

McMahon, C. R., Field, I. C., Bradshaw, C. J. A., White, G. C., \& Hindell, M. A. (2008). Tracking and data-logging devices attached to elephant seals do not affect individual mass gain or survival. Journal of Experimental Marine Biology and Ecology, 360, 7177.

Merkle, J. A., Cherry, S. G., \& Fortin, D. (2015). Bison distribution under conflicting foraging strategies: site fidelity vs. energy maximization. Ecology, 96(7), 1793-1801.

Mingozzi, T., Mencacci, R., Cerritelli, G., Giunchi, D., \& Luschi, P. (2016). Living between widely separated areas: Long-term monitoring of Mediterranean loggerhead turtles sheds light on cryptic aspects of females spatial ecology. Journal of Experimental Marine Biology and Ecology, 485, 8-17. doi:10.1016/j.jembe.2016.08.007

Newell, G. R. (1999). Responses of Lumholtz's tree-kangaroo ( Dendrolagus lumholtzi ) to loss of habitat within a tropical rainforest fragment. Biological Conservation, 91, 181189.

Oosthuizen, W. C., Bester, M. N., Altwegg, R., McIntyre, T., \& de Bruyn, P. J. N. (2015). Decomposing the variance in southern elephant seal weaning mass: partitioning environmental signals and maternal effects. Ecosphere, 6(August), 1-22.

Piper, W. H. (2011). Making habitat selection more "familiar" : a review. Behavioral Ecology and Sociobiology, 65, 1329-1351. doi:10.1007/s00265-011-1195-1 
Postma, M., Bester, M. N., \& De Bruyn, P. J. N. (2013). Spatial variation in female southern elephant seal mass change assessed by an accurate non-invasive photogrammetry method. Antarctic Science, 25(6), 731-740. doi:10.1017/S0954102013000059

R Core Team (2016). R: A language and environment for statistical computing. R Foundation for Statistical Computing, Vienna, Austria. Retrieved from http://www.r-project.org

Shields, W. M., Cook, J. R., Hebblethwaite, M. L., \& Wiles-Ehmann, S. S. (1988). Ideal free coloniality in the swallows. In C. N. Slobodchikolf (Ed.), The Ecology of Social Behavior (pp. 189-228). San Diego: Academic Press.

Simmons, S. E. (2008). Environmental and individual effects on the foraging success of an apex predator, the northern elephant seal (Mirounga angustirostris). Ph.D. thesis, University of California, Santa Cruz.

Simpfendorfer, C. A., Olsen, E. M., Heupel, M. R., \& Moland, E. (2012). Three-dimensional kernel utilization distributions improve estimates of space use in aquatic animals. Canadian Journal of Fisheries and Aquatic Sciences, 69, 565-572. doi:10.1139/F2011179

Stillfried, M., Belant, J. L., Svoboda, N. J., Beyer, D. E., \& Kramer-Schadt, S. (2015). When top predators become prey: Black bears alter movement behaviour in response to hunting pressure. Behavioural Processes, 120, 30-39. doi:10.1016/j.beproc.2015.08.003

Swart, S., \& Speich, J. (2010). An altimetry-based gravest empirical mode south of Africa: 2. Dynamic nature of the Antarctic Circumpolar Current fronts. Journal of Geophysical Research, 115.

Switzer, P. V. (1993). Site fidelity in predictable and unpredictable habitats. Evolutionary Ecology, 7, 533-555.

Tosh, C. A., de Bruyn, P. J. N., Steyn, J., Bornemann, H., van den Hoff, J., Stewart, B. S., ... Bester, M. N. (2015). The importance of seasonal sea surface height anomalies for 

doi:10.1007/s00227-015-2743-4

554

Tosh, C. A., Steyn, J., Bornemann, H., van den Hoff, J., Stewart, B., Plötz, J., \& Bester, M. (2012). Marine habitats of juvenile southern elephant seals from Marion Island. Aquatic Biology, 17(1), 71-79. doi:10.3354/ab00463

Tracey, J. A., Sheppard, J., Zhu, J., Wei, F., Swaisgood, R. R., \& Fisher, R. N. (2014). Movement-Based estimation and visualization of space use in 3D for wildlife ecology and conservation. PLoS ONE, 9(7), e101205. doi:10.1371/journal.pone.0101205

Vander Zanden, H. B., Bolten, A. B., Tucker, A. D., Hart, K. M., Lamont, M. M., Fujisaki, I., ... Bjorndal, K. A. (2016). Biomarkers reveal sea turtles remained in oiled areas following the Deepwater Horizon oil spill. Ecological Applications, 26(7), 2145-2155. doi:10.1002/eap.1366

Vardanis, Y., Nilsson, J.-Å., Klaassen, R. H. G., Strandberg, R. \& Alerstam, T. (2016) Consistency in long-distance bird migration: contrasting patterns in time and space for two raptors. Animal Behaviour, 113, 177-187.

Vermeulen, E., Balbiano, A., Belenguer, F., Colombil, D., Failla, M., Intrieri, E., \& Bräger, S. (2016). Site-fidelity and movement patterns of bottlenose dolphins ( Tursiops truncatus ) in central Argentina : essential information for effective conservation. Aquatic Conservation: Marine and Freshwater Ecosystems, (January 2015). doi:10.1002/aqc.2618

Wakefield, E. D., Cleasby, I. R., Bearhop, S., Bodey, T. W., Davies, R. D., Miller, P. I., ... Hamer, K. C. (2015). Long-term individual foraging site fidelity — why some gannets don' t change their spots. Ecology, 96(11), 3058-3074.

Ward, J. H. J. (1963). Hierarchical grouping to optimize an objective function. Journal of the American Statistical Association, 58(301), 236-244. 
577 Weber, N., Duengkae, P., Fahr, J., Dechmann, D. K. N., Phengsakul, P., Khumbucha, W., ... 578 Newman, S. (2015). High-resolution GPS tracking of Lyle's flying fox between temples 579 and orchards in central Thailand. The Journal of Wildlife Management, 79(6), 957-968. $580 \quad$ doi:10.1002/jwmg.904

581 Wege, M., Tosh, C. A., de Bruyn, P. J. N., \& Bester, M. N. (2016). Cross-seasonal foraging 582 site fidelity of subantarctic fur seals: implications for marine conservation areas. Marine Ecology Progress Series, 554, 225-239. doi:10.3354/meps11798

584 Whisson, D. A., Dixon, V., Taylor, M. L., \& Melzer, A. (2016). Failure to respond to food 585 resource decline has catastrophic consequences for koalas in a high-density population in southern Australia. PLoS ONE, 11(1), 1-12. doi:10.1371/journal.pone.0144348

587 Wolak, M. E., Fairbairn, D. J., \& Paulsen, Y. R. (2012). Guidelines for estimating repeatability. Methods in Ecology and Evolution, 3, 129-137. doi:10.1111/j.2041210X.2011.00125.X

590 


\section{Tables}

593 Table 1: Elephant seals tracked over multiple migrations.

\begin{tabular}{lllllll}
\hline Tag & Sex & $\boldsymbol{N}$ & $\begin{array}{l}\text { Age at } \\
\text { deployments }\end{array}$ & $\begin{array}{l}\text { Years successfully } \\
\text { tracked }\end{array}$ & $\begin{array}{l}\text { Inter-annual UD } \\
\text { overlap }\end{array}$ & $\begin{array}{l}\text { Multi-year UD } \\
\text { overlap }\end{array}$ \\
\hline GG335 & F & 6 & $7,8,9,10,11,12$ & $\begin{array}{l}2007,2008,2009,2010,2011, \\
2012\end{array}$ & $0.65 \pm 0.17$ & $0.57 \pm 0.15$ \\
O0021 & $F$ & 3 & $5,6,7$ & $2007,2008,2009$ & $0.91 \pm 0.03$ & 0.92 \\
O0052 & M & 5 & $4,5,6,9,11$ & $2006,2007,2008,2011,2013$ & $0.74 \pm 0.09$ & $0.64 \pm 0.19$ \\
P0043 & F & 3 & $8,9,10$ & $2007,2008,2009$ & $0.69 \pm 0.13$ & 0.48 \\
P0225 & M & 2 & 8,12 & 2007,2011 & - & 0.74 \\
RR217 & F & 2 & 4,6 & 2009,2011 & - & 0.31 \\
WW061 & $F$ & 4 & $7,10,11,12$ & $2008,2011,2012,2013$ & $0.87 \pm 0.09$ & $0.58 \pm 0.19$ \\
YY039 & F & 2 & 4,7 & 2008,2011 & - & 0.19 \\
YY189 & F & 7 & $2,3,4,5,6,8,9$ & $2006,2007,2008,2009,2010$, & $0.71 \pm 0.09$ & $0.64 \pm 0.19$ \\
\hline
\end{tabular}

594 Mean ( \pm SD) overlap in inter-annual utilization distributions, as well as mean ( \pm SD) overlap

595 in multiple-year utilization distributions, are reported. Only tracks over periods of more than

59630 days (median: 223, range: 38 - 292) were included. 
597 Table 2: Inter-annual and multi-year overlap in 95\% and 50\% three-dimensional utilization 598 distributions (3D-UDs) for southern elephant seals.

\section{$\underline{95 \% 3 D-U D}$}

Inter-annual Multi-year

\begin{tabular}{|c|c|c|c|c|c|}
\hline Tag & $N$ & Day & Night & Day & Night \\
\hline GG335 & 6 & $0.43 \pm 0.1$ & $0.51 \pm 0.15$ & $0.41 \pm 0.15$ & $0.48 \pm 0.11$ \\
\hline 00021 & 3 & $0.56 \pm 0.09$ & $0.58 \pm 0.14$ & 0.38 & 0.5 \\
\hline 00052 & 5 & $0.66 \pm 0.2$ & $0.63 \pm 0.24$ & $0.47 \pm 0.16$ & $0.45 \pm 0.13$ \\
\hline PO043 & 3 & 0.71 & 0.71 & - & - \\
\hline PO225 & 2 & - & - & 0.3 & 0.29 \\
\hline RR217 & 2 & - & - & 0.23 & 0.25 \\
\hline WW061 & 4 & 0.56 & 0.66 & $0.28 \pm 0.07$ & $0.35 \pm 0.01$ \\
\hline YY039 & 2 & - & - & 0.09 & 0.04 \\
\hline \multirow[t]{3}{*}{ YY189 } & 7 & $0.61 \pm 0.14$ & $0.62 \pm 0.11$ & $0.51 \pm 0.17$ & $0.52 \pm 0.15$ \\
\hline & & $0.54 \pm 0.15$ & $0.57 \pm 0.15$ & $0.45 \pm 0.17$ & $0.47 \pm 0.15$ \\
\hline & & $\underline{50 \% 3 D-U D}$ & & & \\
\hline GG335 & 6 & $0.12 \pm 0.07$ & $0.25 \pm 0.22$ & $0.14 \pm 0.17$ & $0.19 \pm 0.15$ \\
\hline 00021 & 3 & $0.38 \pm 0.05$ & $0.44 \pm 0.02$ & 0.21 & 0.26 \\
\hline 00052 & 5 & $0.57 \pm 0.04$ & $0.62 \pm 0.41$ & $0.29 \pm 0.31$ & $0.24 \pm 0.27$ \\
\hline P0043 & 3 & 0.62 & 0.62 & - & - \\
\hline PO225 & 2 & - & - & 0.07 & 0.08 \\
\hline RR217 & 2 & - & - & 0 & 0 \\
\hline WW061 & 4 & 0.22 & 0.56 & $0.02 \pm 0.03$ & 0 \\
\hline YY039 & 2 & - & - & 0 & 0 \\
\hline \multirow[t]{2}{*}{ YY189 } & 7 & $0.37 \pm 0.22$ & $0.44 \pm 0.14$ & $0.22 \pm 0.2$ & $0.3 \pm 0.19$ \\
\hline & & $0.31 \pm 0.21$ & $0.39 \pm 0.23$ & $0.2 \pm 0.22$ & $0.22 \pm 0.2$ \\
\hline
\end{tabular}


600 Table 3: Repeatability ( $r$ ) values of habitat use parameters.

\section{Parameter}

Daytime 95\% 3D UD (kernel volume)

Night-time 95\% 3D UD (kernel volume)

Daytime 50\% 3D UD (kernel volume)

Night-time 50\% 3D UD (kernel volume)

Maximum distance travelled from MI

Bearing of maximum distance point from MI
Repeatability ( $r$ )

0.62

0.60

0.61

0.67

0.62

0.53

601 Repeatability $(r)$ values were calculated from intra-class correlation coefficients.

602 
$603 \quad$ Figure captions.

604

605 Figure 1: Post-moult track locations for nine southern elephant seals tracked over multiple

606 years. The grey-shaded polygon represents the overlap between the 95\% kernel density

607 utilization distributions for all tracks.

608

609 Figure 2: Three-dimensional kernel density utilization distributions (3D-UDs) over multiple

610 years for five southern elephant seals. Darker shading indicates 50\% 3D-UDs and lighter

611 shading 95\% 3D-UDs.

612

613 Figure 3: Hierarchical cluster analysis of migration strategies of southern elephant seals

614 tracked over multiple post-moult migrations, illustrating the three identified behavioural

615 clusters (C1-C3). Locations of migrations identified in each of the clusters are presented in

616 the three maps. Positions of all track locations not within a particular cluster are illustrated in

617 light grey. PO225 is represented in only one migration, due to a comparatively low number of

618 recorded daytime dive depths in 2007. STF $=$ Subtropical Front, SAF = Subantarctic Front,

619 APF $=$ Antarctic Polar Front. Frontal locations were determined from Swart \& Speich (2010).

620 


\section{Acknowledgements}

We are particularly indebted to a number of field assistants who contributed to the instrumenting of focal animals, especially Chris Oosthuizen, Ryan Reisinger, Mia Wege, Martin Postma, Derek van der Merwe, Jean Purdon, Nico Lübcker and Wiam Haddad. The Department of Science and Technology through the National Research Foundation (South Africa), the South African National Antarctic Programme and the Alfred-Wegener-Institut Helmholtz-Zentrum für Polar und Meeresforschung (Germany) provided financial and logistical support. The study further benefited from the Marine Mammals Exploring the Oceans Pole to Pole (MEOP) activity under the International Polar Year. We also wish to thank two anonymous reviewers for their constructive comments that helped improve the manuscript. 
Click here to download high resolution image
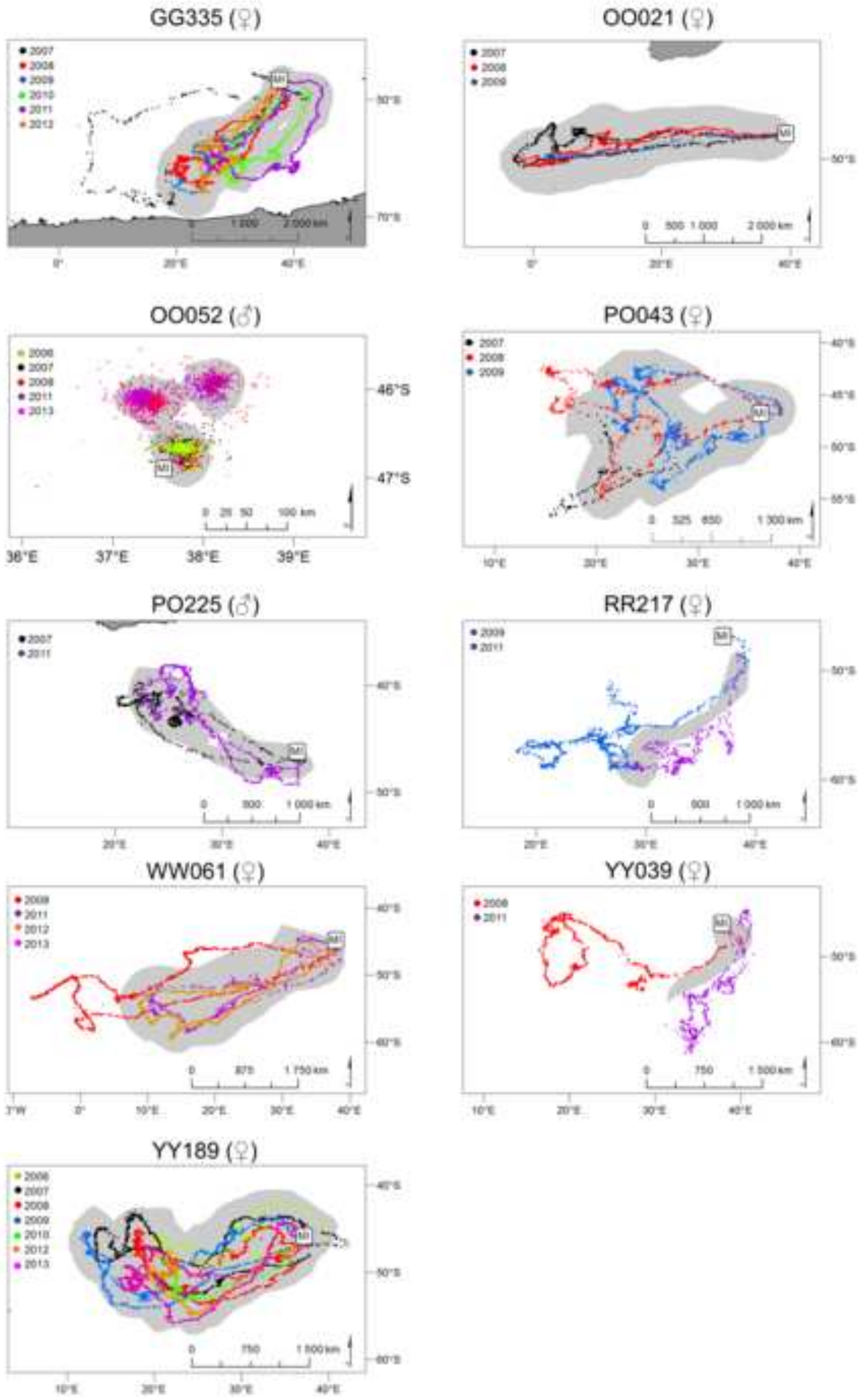
Figure 2
Click here to download high resolution image
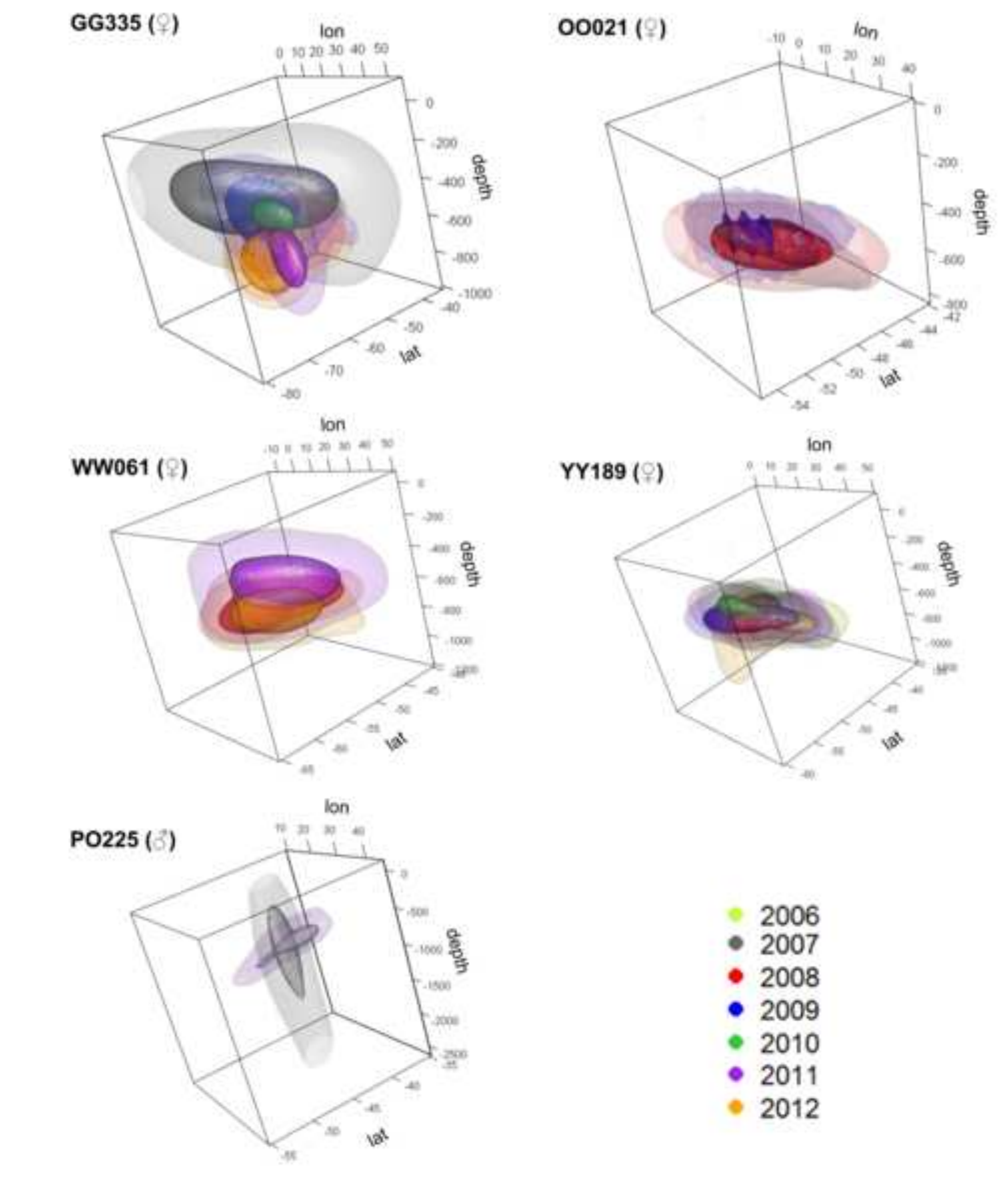

\begin{tabular}{r}
2006 \\
-2007 \\
-2008 \\
-2009 \\
-2010 \\
\hline 2011 \\
\hline \\
2012
\end{tabular}
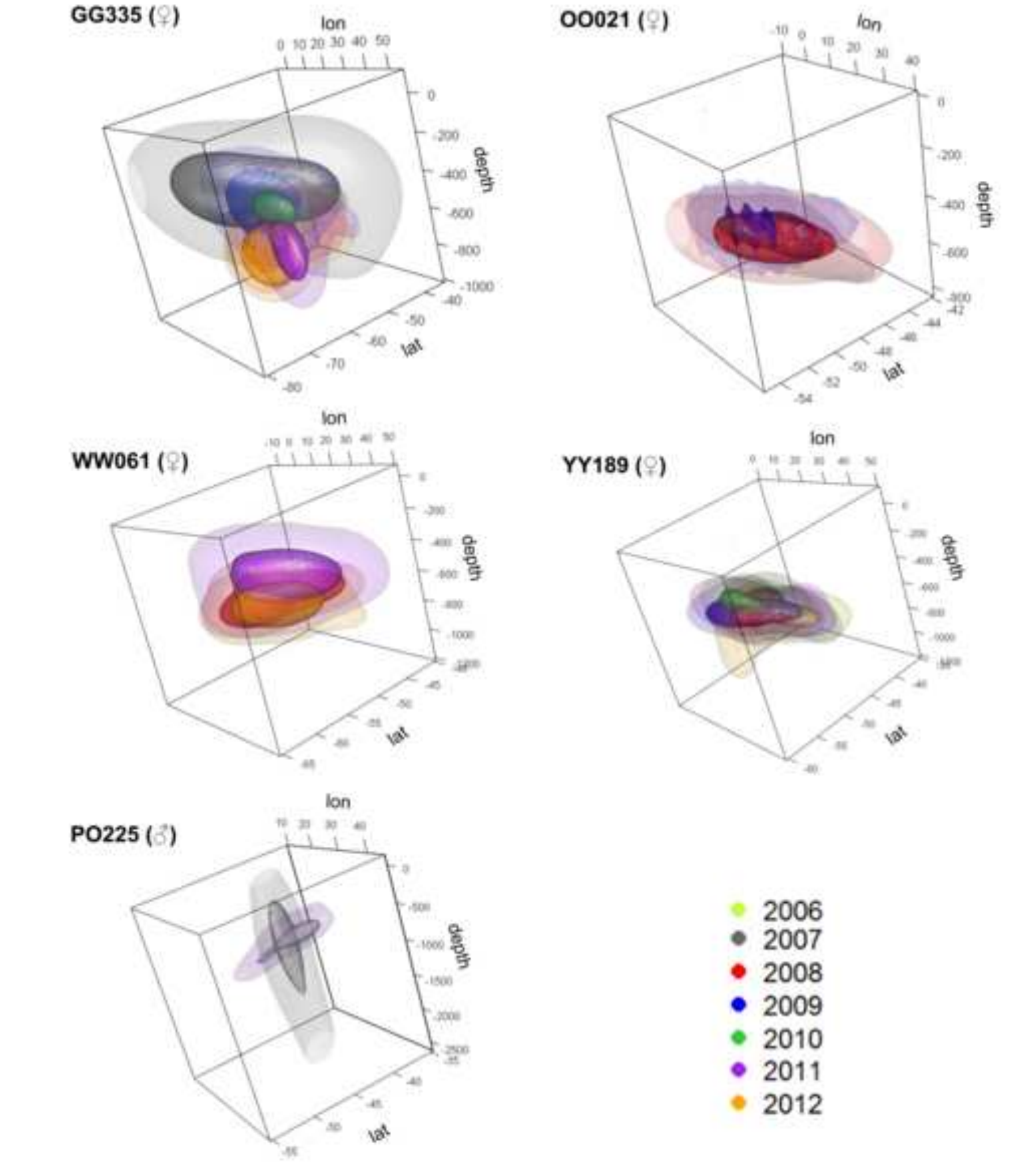
Figure 3
Click here to download high resolution image

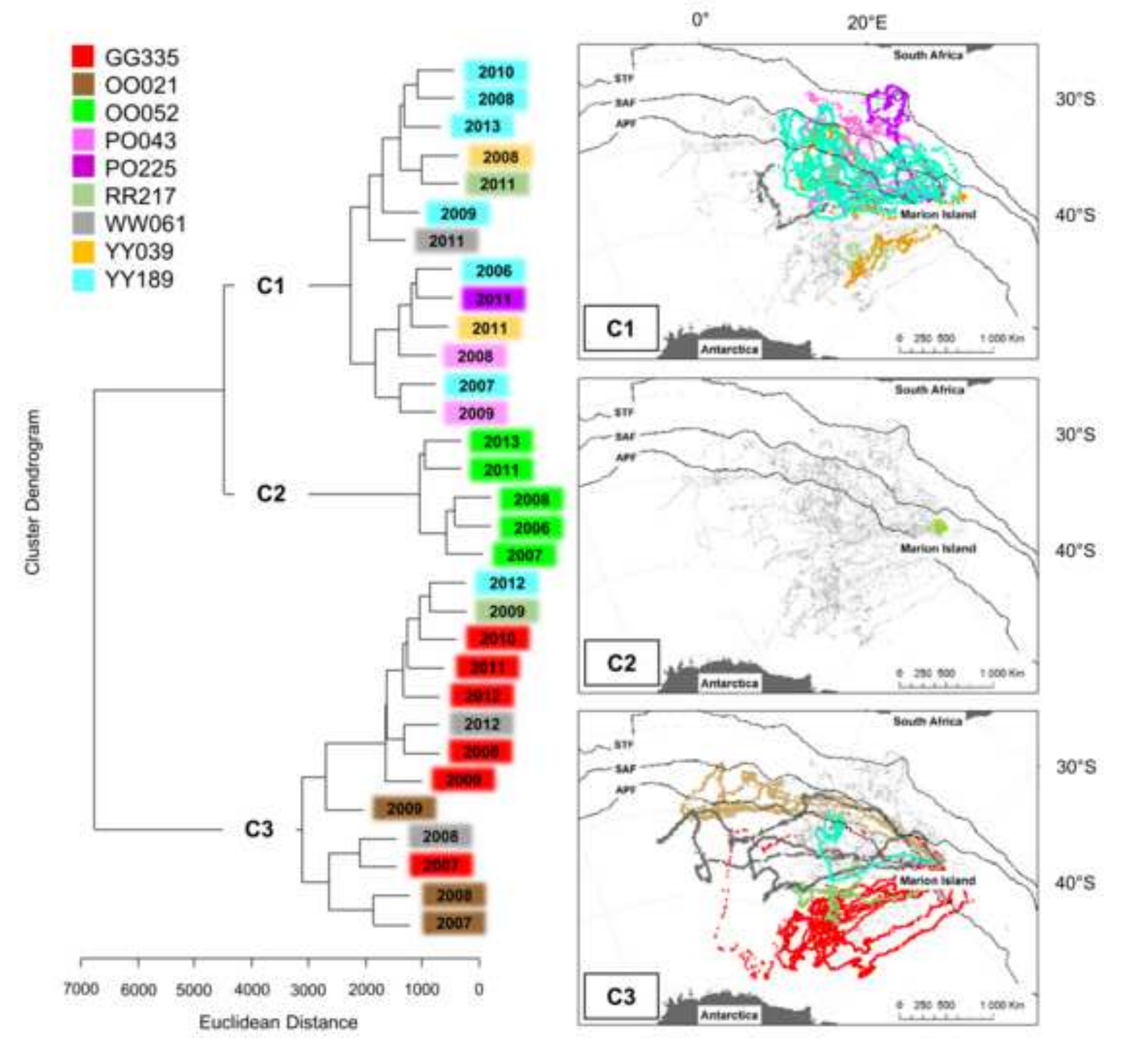

.

